\title{
HEAT CONTENT OF LIQUID CERIUM BY LEVITATION CALORIMETRY
}

\author{
Lyle K. Kuntz
}

M. S. Thesis Submitted to Iowa State University

Ames Laboratory, ERDA

Iowa State University

Ames, Iowa 50010

This report was prepared as an account of work sponsored by the United States Government. Neither the United States nor the United States Energy Research and Development Administration, nor any of

their employees, nor any of their contractors,

subcontractors, or their employees, makes any

warranty, express or implied, or assumes any legal

warranty, express or implied, or assumes any legal

liability or responsibility for the accuracy, completeness

or usefulness of any information, apparatus, product or

infringe privately owned rights.

Date Transmitted: February 1975

PREPARED FOR THE U.S. ENERGY RESEARCH AND DEVELOPMENT ADMINISTRATION UNDER CONTRACT NO. W-7405-eng-82 


\section{DISCLAIMER}

This report was prepared as an account of work sponsored by an agency of the United States Government. Neither the United States Government nor any agency Thereof, nor any of their employees, makes any warranty, express or implied, or assumes any legal liability or responsibility for the accuracy, completeness, or usefulness of any information, apparatus, product, or process disclosed, or represents that its use would not infringe privately owned rights. Reference herein to any specific commercial product, process, or service by trade name, trademark, manufacturer, or otherwise does not necessarily constitute or imply its endorsement, recommendation, or favoring by the United States Government or any agency thereof. The views and opinions of authors expressed herein do not necessarily state or reflect those of the United States Government or any agency thereof. 


\section{DISCLAIMER}

Portions of this document may be illegible in electronic image products. Images are produced from the best available original document. 
This report was prepared as an account of work sponsored by the United States Government. Neither the United States nor the United States Energy Research and Development Administration, nor any of their employees, nor any of their contractors, subcontractors, or their employees, makes any warranty, express or implied, or assumes any legal liability or responsibility for the accuracy, completeness, or usefulness of any information, apparatus, product or process disclosed, or represents that its use would not inf ringe privately owned rights.

Available from: National Terhnical Information Service U. S. Department of Commerce P.O. Box 1553 Springfield, VA 22161

Price: Microfiche $\$ 2.25$ 


\title{
Heat content of liquid cerium \\ by levitation calorimetry
}

by

Lyle K. Kuntz

\author{
A Thesis Submitted to the \\ Graduate Faculty in Partial Fulfillment of the \\ Requirements for the Degree of \\ MASTER OF SCIENCE
}

Department: Chemical Engineering and Nuclear Engineering

Major: Chemical Engineering

\section{Approved:}

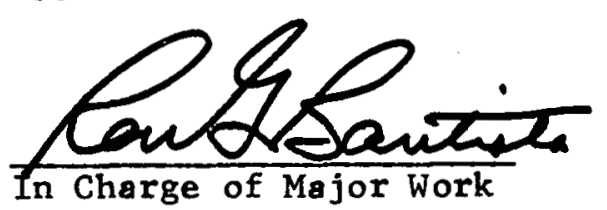

Non. Deunet

For the Major Department

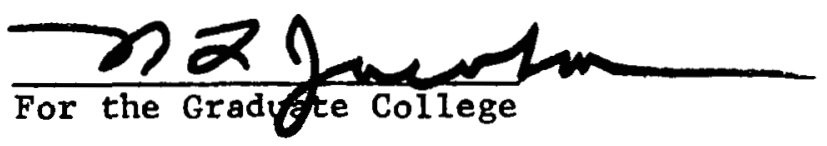

Iowa Etate Univeraity
Ames, Iowa

1975 
TABLE OF CONTENTS

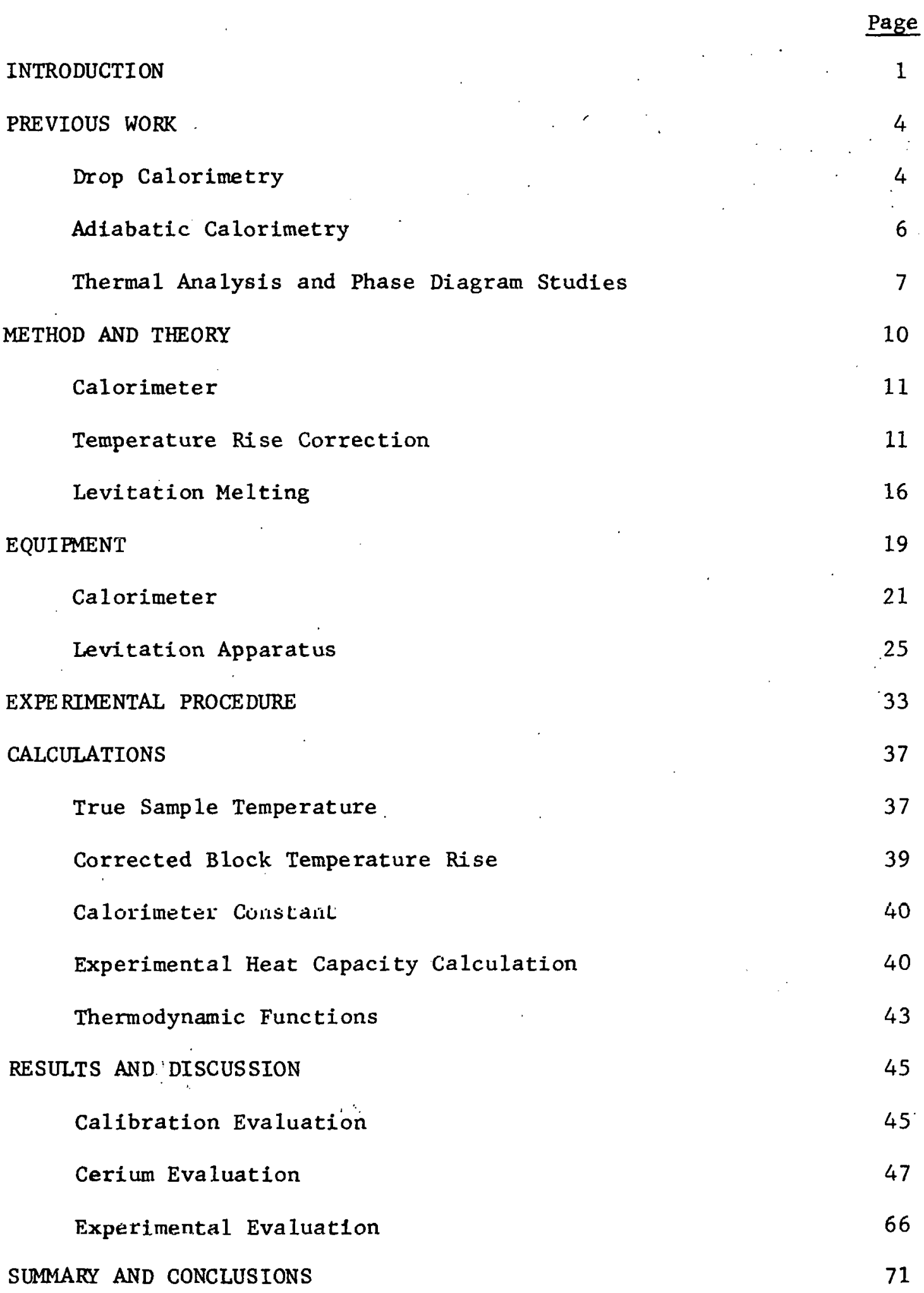


BIBLIOGRAPHY

74

ACKNOWLEDGMENTS 


\section{INTRODUCTION}

Levitation calorimetry is a recent thermodynamic experimental technique which has great potential in liquid state structure and property studies. These studies involve the thermodynamics related to structure transformations from solid to liquid. phase changes and the resulting liquid structure to temperatures $1000^{\circ}$ above the solid melting point. The electronic configuration as related to possible order changes between solids and liquids regulates the magnitude of energy transformations in and between phases. These energy transformations occurring between solids and liquids are constrained by the first and second laws of thermodynamics. From these laws a vast network of equations exist which allow scientists and engineers to investigate various reactions and processes. In order to apply these laws to materials, extensive physical property research must be performed. This research w111 then continually add new dimensions to theories concerning the transformations and structures.

Previous work concerning liquid metals has been hampered by the lack of accurate thermodynamic data. The liquid phase estimation procedures arc more complex than those concerning solids and gases. Predicted results for liquids have usually been inaccurate and rare. The technique of levitation calorimetry has so far proven both its reliability and accuracy concerning the determination of thermodynamic properties of liquid metals. This method has now just begun to fill some of the voids associated with liquid metal properties. 
Present theories have indicated that significant advances have been made concerning liquid state properties. General rules have been established concerning the liquid phase systems. First it is believed that the heat capacities of liquid metals should range from 7 to 8 cal. per mole per degree. Second the heat capacity of liquid metals appears to be approximately constant and third, the heat capacity tends to decrease with increasing temperature. The need for further evaluating these theories dictates extended work with liquid metals. This work was undertaken to add information which would help to improve the theories on liquid state structures.

The levitation calorimetry technique is a version of the popular drop calorimetry method. The heat content of a given sample material is determined from the temperature rise of a callbrated calorimeter. The heat capacity, entropy, enthalpy function, and free energy function may then be calculated from the heat content data. This particular technique is both interesting and unique in that samples are actually levitated in an electromagnetic field with an inert gas as the surrounding medium. The interest is generated from the standpoint of accomplishing experimental work which is new and unusual.

The future contribution of levitation calorimetry to thermodynamic studies of liquid metals is very encouraging. The vast amount of work required concerning elements in the liquid phase is endless. Future problems where levitation calorimetry is most useful involve the evaluation of the heat content of liquid binary and multicomponent alloys. Studies of this nature could yield important correlations between heat capacity and alloy composition. 
The parameters associated with levitation calorimetry make it a useful tool in assembling thermodynamic data. This work will indirectly yield significant information that will help solve future energy shortages. Nuclear systems involving high temperature operations illustrate the need for more thermodynamic data of materials above their melting temperatures. 
PREVIOUS WORK

Three general methods are in use for the experimental determination of high temperature heat contents and heat capacities. These are drop calorimetry, adiabatic calorimetry and data derived from thermal analysis and phase diagram studies. Thermodynamic data for cerium has been obtained using the three methods, with slight variations to each.

The following costion has been divided into three rategories emphasizing the method used to determine the thermodynamic functions of cerium. Each category includes a synopsis of experimental work performed with cerium and the corresponding results.

\section{Drop Calorimetry}

Drop calorimetry procedures are differentiated by. furnace and calorimeter structures. Both resistance and electromagnetic furnaces have been used to heat samples. Two common calorimeter systems are copper block calorimeters and ice calorimeters. Liquid argon calorimeters have also been used for calorimetry work, but will not be discussed in this thesis.

The first calorimeter system uses a furnace to heat an incased sample to a known temperature. The incased sample is then dropped into a copper block calorimeter. Copper block calorimeters are used becalise of quick temperature recovery and ease of assembly. The heat content of the sample is related to the temperature rise of the copper block. This particular arrangement is closely related to levitation calorimetry in that the only difference is the furnace. Levitation 
calorimetry simultaneously heats the sample inductively, while in a levitated position. This procedure then eliminates the need for any type of crucible to contain the sample in the liquid phase.. The accuracy of this system is based on the electric calibration of the calorimeter substantiated by copper evaluation experiments of Stretz and Bonnel1 (2). The copper evaluation experiments authenticate the heat loss corrections and sample temperature measurement calculations. The results of this type of experimental work concerning cerium are given in the results section of this thesis.

A second "drop" method uses a regular resistance furnace to heat an incased sample to be dropped into an ice calorimeter. This process melts the ice which is in thermal equilibrium with the water resulting in a decrease in total volume. This decrease in volume is measured by a mercury displacement method. The volume change is then related to the amount of heat required to melt the ice. This type system was used by Mckeown (3) for his work with cerium, praseodymium, neodymium and samarium. The accuracy of this method depends to a large extent on the purity of the water and mercury, the ability to maintain a constant volume calorimetric system and the ability to accurately measure heat loss corrections caused by convection and radiation. Mckeown's (3) work indicates the liquid phase heat content for cerium to be

$$
\mathrm{H}_{\mathrm{T}}-\mathrm{H}_{\mathrm{O}}=9.345(\tau)+680 \text { cal/mole }
$$

where $t$ is in degrees Celsius. Converting this to the $298.15^{\circ} \mathrm{K}$ reference state gives 


$$
\mathrm{H}_{\mathrm{T}}-\mathrm{H}_{298.15}=9.345 \mathrm{~T}-2033 \mathrm{cal} / \mathrm{mole}
$$

where $T$ is in degrees Kelvin. The heat capacity of cerium is $9.345 \mathrm{cal}$ per mole per degree and the heat of fusion is $1238 \mathrm{cal}$ per mole. These values were determined from four experimental values above the melting point of $1077{ }^{\circ} \mathrm{K}$. The four values were taken in the temperature range $1084{ }^{\circ} \mathrm{K}$ to $1374{ }^{\circ} \mathrm{K}$.

\section{Adiabatic Calorimetry}

The adiabatic calorimetry technique is the second type of calorimetric studies used in the thermodynamic studies of liquid cerium. This method involves the repetitive heating of an incased sample within an adiabatic calorimeter. A known amount of heat is applied to the sample, resulting in a higher temperature. Several commercial adiabatic calorimeters work by this principle. The sample is heated from an internal resistance heater at constant wattage while under adiabatic conditions. The sample is incased in tantalum which is incased in platinum. Surrounding this platinum container is a nickel sphere at which adiabatic conditions exist. The saúple Lemperature was measured on the external surface of the tantalum crucible by a thermocouple. This temperature and the temperature of the surrounding nickel sphere are automatically controlled to give an ideally zero temperature difference. The zero difference is maintained by the heating of the nickel sphere by an external furnace. This equipment type was used by Chiotti et a1. (4) for the experimental determination of the heat of fusion of cerium and several other elements and compounds. Possible drawbacks to the accuracy 
of this type of system include the maintaining of near uniform adiabatic conditions at the nickel sphere, the possibilities of thermal gradients within the sample and the temperature measurements of the sample from the external surface of the crucible. The results of their work yielded a heat of fusion for cerium equal to $1305 \mathrm{cal}$ per mole which is in good agreement with McKeown's (3) work. No heat capacity measurements were made.

\section{Thermal Analysis and Phase Diagram Studies}

The thermal analysis technique involves the estimation of the heat capacity and heat of fusion by analyzing the heating and cooling curves of a given sample. These results are then compared to similar results for a sample of known heat capacity and heat of fusion.

Cavallaro (5) applied this technique to the evaluation of the heat of fusion for cerium and praseodymium. The heat of fusion for cerium was reported as 5500 cal per mole.

This method while being most rapid to perform requires intensive precautions to obtain reproducible data.

Phase diagram studies involve determining the heat of fusion for various materials through the use of binary phase change studies. Freezing point data has been used to establish reasonable estimates of the heat of fusion for many different elements. Kelley (6) has presented the format for calculating the heats of fusion through the use of binary systems. 
For cerium, Kelley (6), referred to the work of Vogel (7). Vogel's (7) work consists of freezing point studies concerning the cerium-iron system. From Vogel's (7) data Kelley (6) determined the heat of fusion for cerium to be 2120 cal per mole. Kelley (6) believed this value to be slightly low and referred to $2200 \mathrm{cal}$ per mole in a revised publication (8) in 1960. Kelley (8) gives the heat capacity of liquid cerium to be $8.00 \mathrm{cal}$ per mole per degree, referring to the estimate given by Stu 11 and Sinke (9).

The disadvantages of these calculated values are given by Kelley as the lack of available information concerning activity coefficients, molecular species present in solutions, accurate analysis of separated solid components upon cooling and the lack of thermal equilibrium upon heating and cooling.

Kojima and Kikuchi (10) have employed the phase diagrams of ceriumgold, cerium-silver, cerium-copper, and cerium-thallium systems to evaluate the heat of fusion for cerium. Their values are 3030,2520 , 2340 and $4490 \mathrm{cal}$ per mole, respectively. An average value of $3090 \mathrm{cal}$ per mole was given as a good estimate of the heat of fusion for cerium.

The work of Chlotti et al. (4) supports that of Mckeown (3) in establishing the heat of fusion for cerium to be approximately $1300 \mathrm{cal}$ per mole. This however does not prove the reliability of Mckeown's (3) work above the melting temperature of $1077^{\circ} \mathrm{K}$. Heát content values above $1077^{\circ} \mathrm{K}$ could be slightly luw due to previluusly discussed disadvantages of the ice calorimeter technique.

The heat of fusion estimates of Cavallaro (5), Kelley (6) and Kojima and Kilcuchi (10) occm to be approximately $1000 \mathrm{cal}$ per mole too 
large. This could be accounted for by the $700 \mathrm{cal}$. per mole heat of transition at $1000 \mathrm{~K}_{\mathrm{K}}$. Their results could include both heats of transition and fusion since the work is empirical.

Further insight is readily available as demonstrated by the recent work of Sommer (11). Analysis of changing binding conditions caused by charge transfers and strain energies in liquid phases have yielded enthalpy of mixing calculations. These quantitative calculations have been done by means of a pseudo potential theory. This relates to the clustering effect of metal atoms in liquid phases as presented by Stretz (1). This clustering of atoms could produce unusual results concerning the thermodynamic evaluation of liquid metals.

The previously reported work demonstrates the need for further work on the thermodynamic properties of liquid cerium. 
METHOD AND THEORY

The continued use of levitation calorimetry has been justified by the relative ease of taking data in the temperature region where it is otherwise impossible and by the accuracy of the data obtained. The technique involves a copper block calorimeter subjected to a constant temperature surrounding and an electromagnetic levitation melting apparatus serving to regulate the temperature of a liquid sample. The copper block calorimeter was chosen due to ease of operation while maintaining a relatively high degree of accuracy in the overall method (usually better than $\pm 0.5 \%$ ). The electromagnetic levitation of liquid samples is well suited especially when these samples are highly reactive. Past work involving the use of crucibles has been difficult due to the dissolution of the crucible material into the liquid sample $(12,13)$. The levitation technique does away with the crucible, eliminating sample contamination. Levitation calorimetry has been successfully employed to evaluate the heat contents of liquid copper and platinum by Chaudhuri et al. (14), copper, platinum, niobium and zirconium by Bonnel1 (2) and lanthanum, praseodymium, neodymium and yttrium by Stretz (1). Treverton and Margrave (15, 16) have reported successful work with cobalt, palladium, iron, titanium and vanadium A more detailed description of the method is given in the following sections. 


\section{Calorimeter}

The technique involved is simply that of a constant temperature block in a constant temperature surroundings. The calorimeter is heated by a sample of known weight to a final temperature while constantly being subjected to the initial surrounding temperature. The temperature rise of the block is recorded as a function of time. After heat usage rnrrestinns are made, the heat content of the sample is calculated from the relation

$$
\mathrm{H}_{\mathrm{T}}-\mathrm{H}_{\mathrm{T}}=\left(\mathrm{MC}_{\mathrm{p}} \Delta \mathrm{T}\right) / \mathrm{m}
$$

where $\left(\mathrm{H}_{\mathrm{T}}-\mathrm{H}_{\mathrm{T}_{j}}\right)$ is the change in heat content of a given sample from $\mathrm{T}_{j}$, the reference temperature, to $\mathrm{T}$, the initial sample temperature, $M$ is the molecular weight of the sample, $C_{p}$ is the heat capacity of the calorimeter in cal.per degree, $\Delta T$ is the change in temperature of the copper block and $m$ is the mass of the dropped sample. The reference temperature is the temperature at which the copper block is calibrated and is usually $298.15 \mathrm{~K}_{\mathrm{K}}$. Corrections for the heat leakage from the copper block to the surroundings are described below.

\section{Temperature Rise Correction}

Since an insulating gas void is located between the block and the constant temperature reservoir, convective heat transfer is virtually eliminated, leaving radiative and conductive transfer. One direct heat leak route is through the quartz probe lead. However, this leakage has been estimated at: less than $0.0001^{\circ} \mathrm{C}$ per 10 seconds and does not affect 
the assumption of a linear tota 1 heat leak as examined by Stretz (1).

The rate of heat transfer is assumed to follow Newton's law of cooling and is given by

$$
\frac{d H e}{d t}=-k\left(T-T_{j}\right)
$$

where dHe/dt is the change in heat content of the block per unit time, $k$ is a constant, $T$ is the block temperature and $T_{j}$ is the temperature of the constant temperature bath.

At the beginning of each experiment the copper block was at a lower temperature than the surroundings. The result of one run in the calorimeter yields three temperature-time profiles. These are the initial period when the block is increasing in temperature at a constant rate, the main period when the sample raises the block temperature, and the final period when the temperature of the block gradually increases nearing the temperature of the surroundings. For the initial and final periods the temperature time curve is nearly linear. Figure 1 shows these three periods which are typical of each run.

During the main period, the block increases in temperature because of the hot sample and the heat loss to the surroundings. This heat exchange is described by the relation

$$
\Delta H_{s}+\Delta H_{e}=C_{p}\left(T_{f}-T_{i}\right)
$$

where $\Delta H_{s}$ is the heat content change of the block due to the heat of the sample, $\Delta \mathrm{Hl}_{\mathrm{e}}$ is the heat content change of the block due to the heat exchange to the surroundings, $C_{p}$ is the heat capacity of the block 


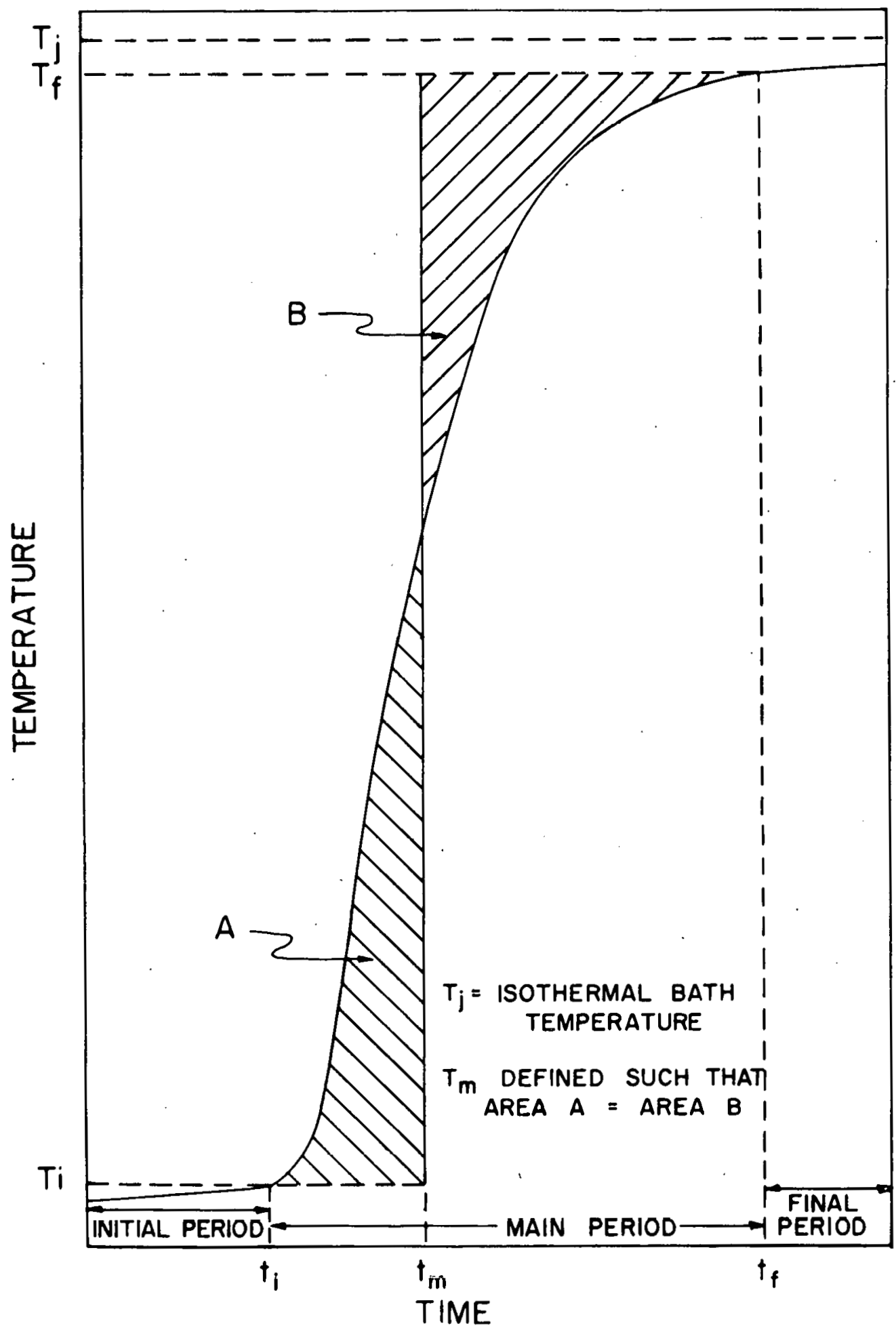

Figure 1. Temperature versus time curve for the copper block calorimeter. 
and $T_{i}$ and $T_{f}$ are the beginning and ending temperatures of the block relative to the main time period limits, $t_{i}$ and $t_{f} \cdot$ By definition:

$$
\Delta H_{s}=C_{p} \Delta T
$$

and

$$
\Delta \mathrm{H}_{\mathrm{e}}=\mathrm{C}_{\mathrm{p}} \Delta \mathrm{T} \text { correction }
$$

where $\Delta \mathrm{T}$ is the temperature rise due to the sample and $\Delta \mathrm{T}_{\text {correction }}$ is the temperature change due to the surroundings. Rearranging and substituting gives

$$
\Delta \mathrm{T}=\mathrm{T}_{\mathrm{f}}-\mathrm{T}_{\mathrm{i}}-\Delta \mathrm{T}_{\text {correction }} .
$$

Applying Newton's law of cooling yields

$$
\Delta T_{\text {correction }}=-\frac{k}{C_{p}} \int_{t_{i}}^{t_{f}}\left(T-T_{j}\right) d t \text {. }
$$

The rate of change of temperature at time $t_{i}$ is

$$
\left.\frac{d T}{d t}\right|_{t_{i}}=-\frac{k}{c_{p}}\left(T_{i}-T_{j}\right)
$$

and at time $t_{f}$ is

$$
\left.\frac{d T}{d t}\right|_{\tau_{f}}=-\frac{k}{C_{p}}\left(T_{f}-T_{j}\right) .
$$

Establishing a midtime, $t_{m}$, to Equation 8 yields

$$
\Delta T_{\text {correction }}=-\frac{k}{c_{p}}\left[\int_{t_{i}}^{t}\left(T-T_{j}\right) d t+\int_{t_{m}}^{t}\left(T-T_{j}\right) d t\right] \text {. }
$$

Introducing $T_{i}$ and $T_{f}$ by integral manipulation gives 


$$
\begin{aligned}
& \Delta T_{\text {correction }}=-\frac{k}{C_{p}}\left[\int_{t_{i}}^{t_{m}}\left(T_{i}-T_{j}\right) d t+\int_{t_{i}}^{t}\left(T-T_{i}\right) d t\right. \\
& \left.+\int_{t_{m}}^{t_{f}}\left(T_{f}-T_{j}\right) d t+\int_{t m}^{t_{f}}\left(T-T_{f}\right) d t\right]^{i}
\end{aligned}
$$

The midtime is defined as

$$
\int_{t_{i}}^{t_{m}}\left(T-T_{i}\right) d t=-\int_{t_{m}}^{t_{f}}\left(T-T_{f}\right) d t
$$

and is represented in Figure 1. Applying this definition while $T_{i}$, $\mathrm{T}_{f}$ and $\mathrm{T}_{j}$ are constant and integrating equation 12 gives

$$
\Delta T_{\text {correction }}=-\frac{k}{C_{p}}\left[\left(T_{i}-T_{j}\right)\left(t_{m}-t_{i}\right)+\left(T_{f}-T_{j}\right)\left(t_{f}-t_{m}\right)\right] .
$$

Substituting equations 9 and 10 into this yields

$$
\Delta T_{\text {correction }}=\left.\frac{d T}{d t}\right|_{t_{i}}\left(t_{m}-t_{i}\right)+\left.\frac{d T}{d t}\right|_{t_{f}}\left(t_{f}-t_{m}\right)
$$

Final substitution yields

$$
\Delta H=\frac{M C}{m}\left[T_{f}-T_{i}-\left.\frac{d T}{d t}\right|_{t_{i}}\left(t_{m}-t_{i}\right)-\left.\frac{d T}{d t}\right|_{t_{f}}\left(t_{f}-t_{m}\right)\right]
$$

where the slopes $(d T / d t)_{t_{\mathfrak{I}}}$ and $(d T / d t)_{t_{f}}$ are measured from the temperature versus time curves for the initial and final periods and where $T_{j}$ is the isothermal surrounding temperature.

To simplify the raw data reduction a numerical integration technique is applied to equation 8 . The computer numerical technique and the expanded form above yield identical results. 
Levitation Melting

Induction heating involves the placement of a sample in a nonunfform, alternating, electromagnetic fleld. The eddy currents established within the sample enable the sample to be supported without the aid of a container if the vertical component of the field is equal to or greater than the weight of the sample. As described by Jenkins et al. (17), the force on the sample depends on the field strength and gradient. Stabilization of the sample occurs by placement of a uniform opposing force against the sample. Figure 2 illustrates how a sample under these restraints will reside at the position of minimum field strength. Various coil designs have been investigated by Jenkins et al. (17), Okress et al. (18) and Wroughton et al. (19). Levitated materials and their optimum coil designs have been discussed by Bonne11 (2) and Stretz (1).

Sample temperature depends upon the position of the sample in the field, the rate of heat loss, the shape of the coil, the power to the coil and the weight of the sample. Identical sample temperatures can be maintained by different parameter adjustments. For example, if the weight of a sample is increased, the sample will sit lower in the field yielding a higher temperature, assuming all other variables are held constant. However, if samples of constant mass are considered, decreasing the power causes the sample to sit lower in the coil causing an increase in the temperature of the sample. In both instances, the sample is subjected to more electromagnetic field intensity. 
SOLENOID COIL

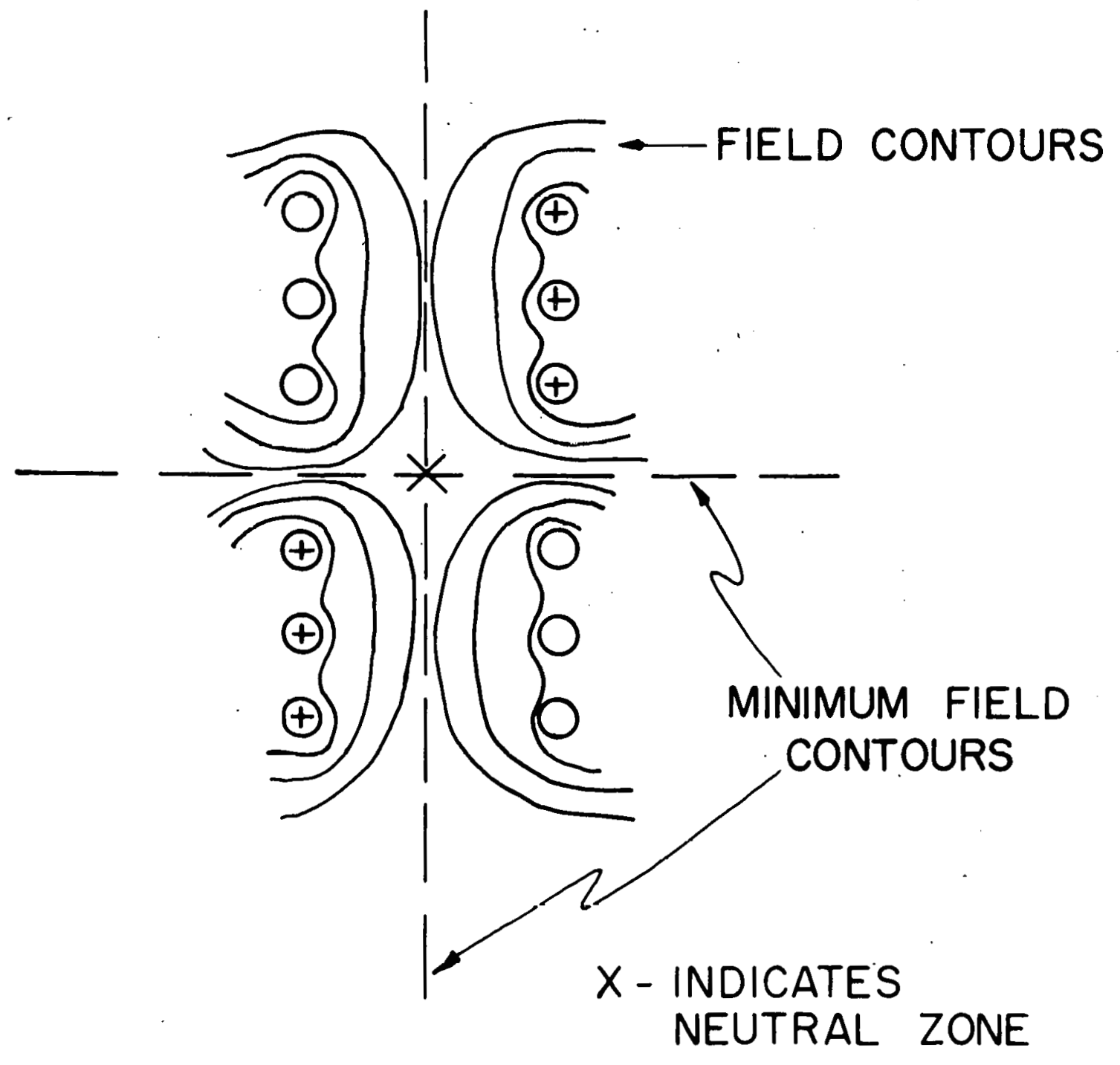

Figure 2. Levitation field contours for a typical solenold $\operatorname{col} 1$. 
The rate of sample heat loss is regulated by the inert atmosphere composition. This argon-helium mixture can be easily regulated, usually giving lower temperatures for a pure helium atmosphere and higher temperatures for a pure argon atmosphere. Maximum temperature could be obtained if the operation was performed under vacuum, where heat losses would only be by radiation. Under vacuum, sample vaporization would add to temperature measurement problems, equipment assembly would be hampered and intense corona discharge would be evident from the levitation coil.

Bonnel1 (2) has discussed designs of levitation melting systems, including the matching of coil impedance to high-frequency generators. However making efficient coil designs appears to be an empirical problem, with experience being the best guide. 


\section{EQUIPMENT}

The experimental equipment involved in levitation calorimetry may be divided into two major sections. These two sections and their components. are listed as follows:

1. Calorimeter

a) Constant temperature bath

b) Calorimeter jacket and block

c) Temperature monitoring equipment

d) Miscellaneous support equipment

2. Levitation apparatus

a) High-frequency generator

b) Matching transformer

c) Current adjusting type (C.A.T.) generator controller

d) Modified sample drop contro1ler

e) Levitation. coils

f) Levitation chamber

g) Drop tube

h) Sample temperature measurement apparatus.

A more detailed description of each component is given below. Figure 3 shows a schematic view of all the major components. Exact dimensions and individual illustrations are given by stretz (1). 


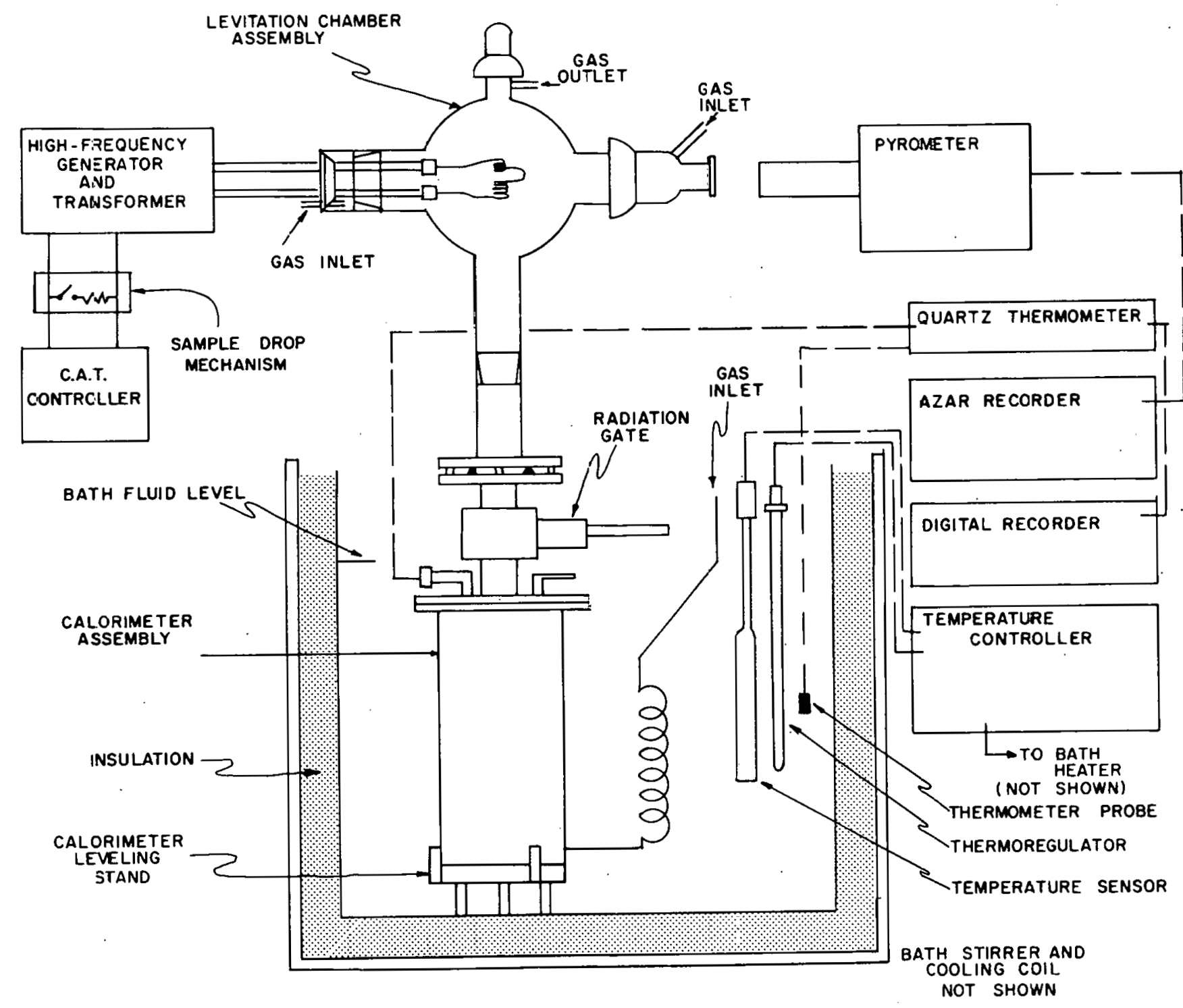

Figure 3. Levitation calorimetry apparatus. 
Calorimeter

Constant temperature bath

The constant temperature bath was a large steel tank 18 inches in diameter by 20 inches in depth. The tank was contained in a wooden box with a minimum of three inches of vermiculite insulation around the circumference and the bottom.

The tank was filled with water to a depth just above the calorimeter assembly and was heated by a 500 watt Calrod heater. Bath cooling was provided by immersing a 10 foot, $1 / 4$ inch diameter water cooled copper tube. The bath was agitated by an impeller type stirrer.

The power output for the Calrod heater was supplied by a Bayley Mode1 非252 precision temperature controller with $\pm 0.0001{ }^{\circ} \mathrm{C}$ tolerance over a period of 8 hours. Due to generator interference, the control system was modified by the use of a Precision Scientific 非62541 Microset Thermoregulator. The interference generated caused a power increase, raising the bath temperature. With the additional controller and a normally closed relay, the bath temperature could be maintained at $\pm 0.006{ }^{\circ} \mathrm{C}$, while the generator was in operation.

The temperature of the bath was monitored by a quartz thermometer which is discussed in the monitoring equipment section.

\section{Calorimeter jacket and block}

The calorimeter jacket was made of 4 inch $0 . D$. brass tubing with a $1 / 4$ inch wal1. The bottom was made from $1 / 4$ inch brass plate. A gas inlet port was provided at the bottom of the jacket. The lid of the jacket was constructed from $1 / 4$ inch brass plate with outlets for the 
block cover gate lever and the thermometer lead. A one inch I.D. tube extended up from the center of the lid to a one inch sliding gate valve which served as a radiation gate. A one inch I.D. tube extended from the gate valve to a 4-7/8 inch flange. This flange provided the mounting for the drop tube. All metal portions were chrome plated to reduce radiative heat transfer. The total height from bottom to flange top is approximate $1 \mathrm{y} 11-1 / 2$ inches.

The calorimeter block was a copper cylinder $2-1 / 2$ inches in diameter and 7-3/4 inches in height. A 3 inch deep, tapered recess, 1-1/4 inch diameter at the top, was used to accommodate the copper sample receiving we11. This type system was used to simplify the taking of sample weights.

The temperature sensing probe for the quartz thermometer was inserted in a drilled hole near the bottom of the copper block. The position of the probe relative to the receiving well is not critical as long as the probe is not moved after electrical calibration. The position of the probe was chosen to avoid transient temperature responses.

The receiving well 1 id was $1 / 8$ inch thick and made of copper. The operating mechanism from the lid to the outside of the jacket was made of nyion to minimize heat loss.

The outside surface of the calorimeter block was gold plated to reduce heat exchange between the block and jacket. A11 surfaces were kept well polished. A schematic drawing of the calorimeter assembly is given in Figure 4 as presented by stretz (1). 


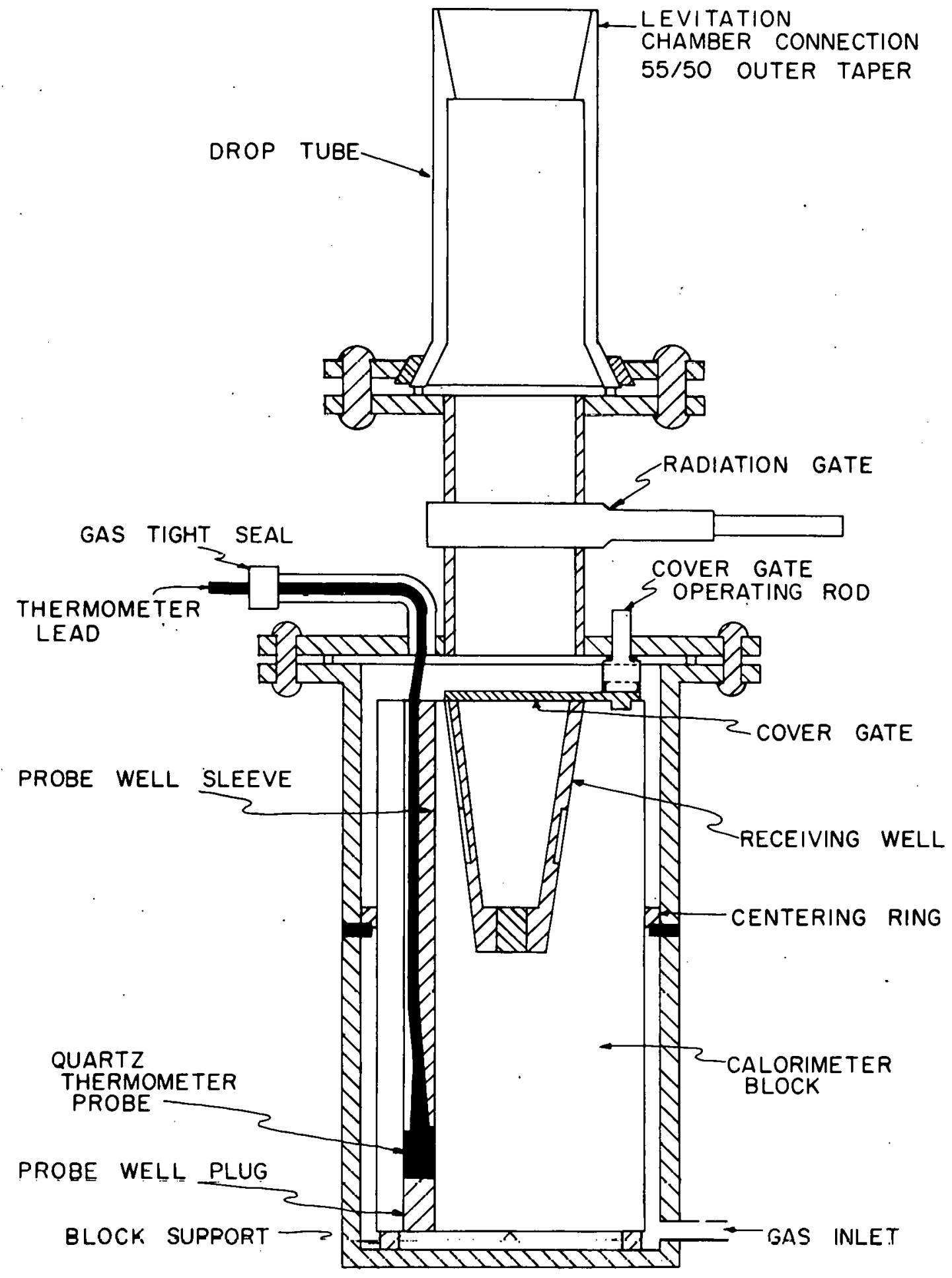

Figure 4. Copper block calorimeter assembly. 
Temperature monitoring equipment

The temperature of the calorimeter block and constant temperature bath was monitored with a Hewlett-Packard 2801-A Quartz Thermometer. Convenience and accuracy were the primary reasons for this type of operation. Direct readings were recorded on paper tape by a HewlettPackard 562-A Digital Recorder.

The basic principle of the quartz thermometer involves the cutting of a quartz crystal in such a way that 1 ts resonance frequency varies linearly with temperature. This frequency is electronically compared to a reference oscillation and gives temperature readings to 5 decimal accuracy in degrees Celsius. Calibration corrections for the matching of probes to a specific base unit are included with each probe.

The probe lead is a teflon coated coaxial cable. It exits the jacket at the top surface where it is sealed by a swagelock fitting using a tefion ferrule.

\section{Miscellaneous support equipment}

Because water at constant temperature was needed for the constant temperature bath, the in-house water supply was directed through two auxiliary constant temperature baths. The secondary baths were controlled to within $\pm 0.1{ }^{\circ} \mathrm{C}$ at approximately $24^{\circ} \mathrm{C}$. This system served to damp out the inconsistencies in the house water system temperature.

A system was designed to remove traces of oxygen from the heliumargon purge gas. This was accomplished by passing the gas through a titanium sponge at $600{ }^{\circ} \mathrm{C}$. After being cooled to room temperature, the gas next passed through a bed of molecular sieves where any residual 
molsture was removed. The gas stream was brought to the temperature of the main bath by passing it through a coil of $1 / 4$ inch copper tube immersed in the bath. Finally, the gas was fed to the calorimeter assembly through 3 different ports to reduce gas currents inside the assembly.

Levitation Apparatus

\section{High-frequency generator}

The high-frequency generator used as the furnace for this study was a Lepel model 非T-20-3-KC-F-S which operated at approximately $450 \mathrm{kh}$.

\section{Matching transformer}

A transformer between the generator and the small work coil was needed to match impedances. This transformer was wound at the Ames Laboratory and consisted of a 12 turn, 6-3/4 inch diameter primary coil made of $1 / 4$ inch copper tubing and a 3-1/2 turn, 7-1/2 inch diameter secondary coil made of $1 / 2$ inch copper tubing. Polyethylene was used between the coils for insulation. Glyptol insulating paint was used to cover the entire transformer surface to eliminate shorting. The water for the primary coil was supplied by the generator cooling system and for the secondary and levitation coils by the in-house water. A booster pump was used to increase the flow rate of water through the work $\operatorname{col} 1$, allowing the generator to be used at higher power levels. 
Current adjusting type (C.A.T.) generator controller

The power to the levitation coil from the generator was regulated by a Leeds and Northrup M-Line C,A.T. (current adjusting type) Controller, Mode1 C-1A. This controlling system was used in place of the generator power control.

Modified sample drop controller

Previous experiments involving sample drops from the levitation coil field were performed by shutting off the power to the levitation coil. This procedure was proven ineffective with many lost experiments. due to erratic sample drop paths.

A sample that is dropped from levitation must fall approximately $30 \mathrm{~cm}$.through a one inch opening into the calorimeter assembly. When the generator is shut off, residual magnetic fields due to the electronic structure of the generator sometimes altered the path of the sample as it leaves the levitation coil. In most instances, the sample falls on the flange area surrounding the entrance to the calorimeter jacket.

To eliminate this problem, a control was installed between the generator and the current adjusting type controller which in affect lowered the power quickly to zero. In this way, constant fields around the levitation coil diminished rapidly without any residual field surges. The control consists of a variable shunt between the two leads going from the C.A.T. controller to the generator. The shunt is controlled by a toggle switch and is variable from 0 to 10,000 ohms. In this 
fashion the C.A.T. controller can be adjusted to a minimum power level when the shunt is activated.

Under levitation conditions the shunt was on an open circuit. At drop time, the shunt circuit was closed reducing the power directed to the levitation coil to a minimum value preset by the variable shunt resistance :

Reducing the power manually rather than using the shunt was ineffective. The time involved in turning the power control down to a level where the sample would fall, allowed the sample temperature to decrease; yielding incorrect results. As a result, increasing power levels gave increasing sample temperature errors. This addition to the equipment is shown in Figure 3.

Levitation coils

The levitation coils were wound from $1 / 8$ inch diameter soft copper tubing. Work coil designs were made by trial and error, but were patterned after those used by Stretz (1) and Bonnel1 (2). Three basic forms were used for the levitation of cerium. These forms were solenoid, conical and reverse conical. Schematics of these basic shapes are given in Figure 5. The success and variations of these coils are discussed in the results section.

\section{Levitation chamber}

The levitation chamber was fashioned from a one liter round bottom flask, modified to provide several ports. One side of the flask was opened to a $71 / 60$ ground glass inner taper.; This connected to a $71 / 60$ ground glass outer taper enclosed on one end by a rubber stopper. The 


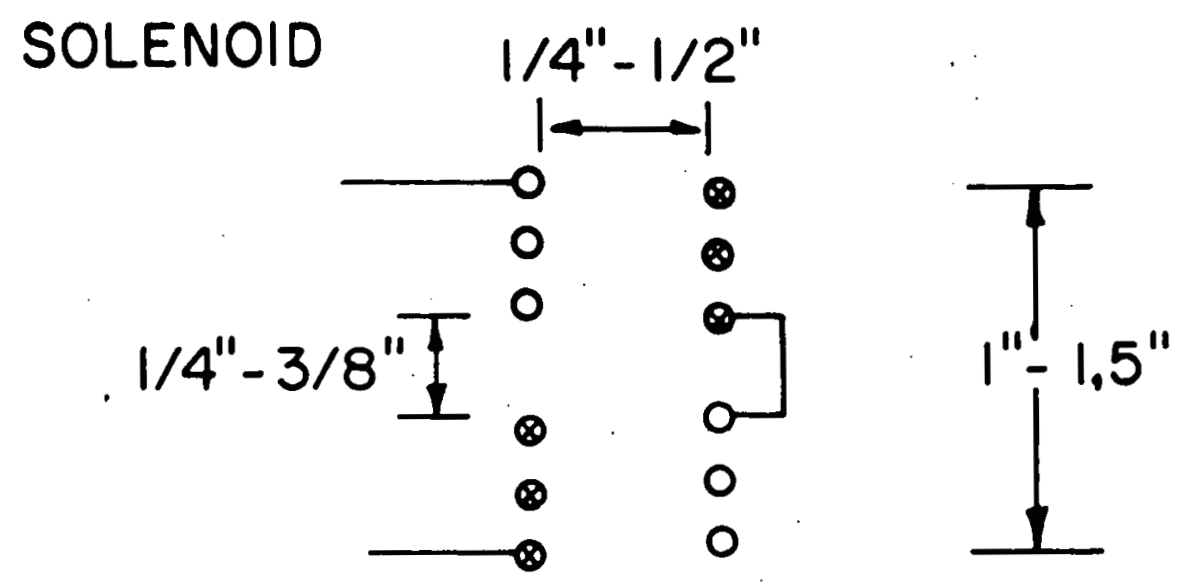

CONICAL

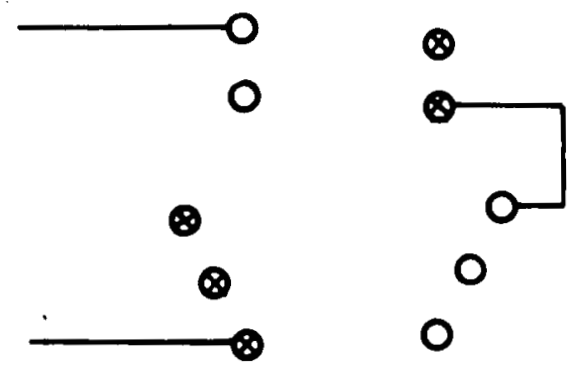

REVERSE CONICAL

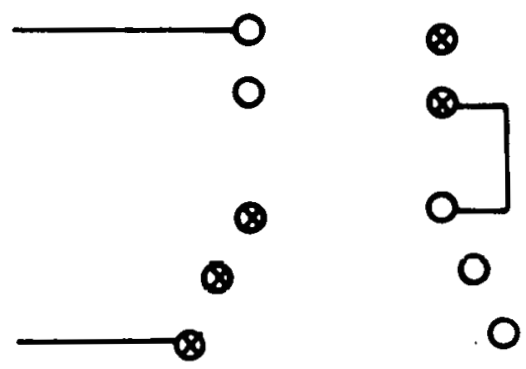

Figure 5. Three basic types of levitation coils. 
coil leads and:a purge gas inlet passed through this stopper. This format was used so that when the chamber was removed the seal on the rubber stopper would not have to be broken. The extra gas inlet allowed more efficient purging and more uniform gas flow around the levitation $\cot 1$.

On the opposite side of the flask was a port terminating with a 65/40 ground glass ball joint. An extension from this supported a quartz pyrometer window and a gas inlet used to sweep fumes away from the window and to provide uniform gas flow around the levitation coil.

A third port was provided at the top of the flask for sample insertion, purge gas removal and drop path alignment. Offset slightly from this port, was a small tube which allowed the extension of a glass sample holder to pass through.

The bottom of the chamber opened to a 55/50 ground glass inner taper which connected to the drop tube. A schematic drawing of the chamber may be found in Figure 6 .

\section{Drop tube}

The drop tube section consisted of a 2 inch. O.D. pyrex column fitted with a 55/50 ground glass outer taper to be connected to the levitation chamber. The bottom of the column was clamped to the flange of the calorimeter jacket incorporating an "O-ring" seal. The total length of the drop tube assembly was approximately 6-1/2 inches.

\section{Sample temperature measurement equipment}

The temperature of the levitated sample was determined with a Leeds and Northrup 8641 Precision Automatic Optical Pyrometer with the output 


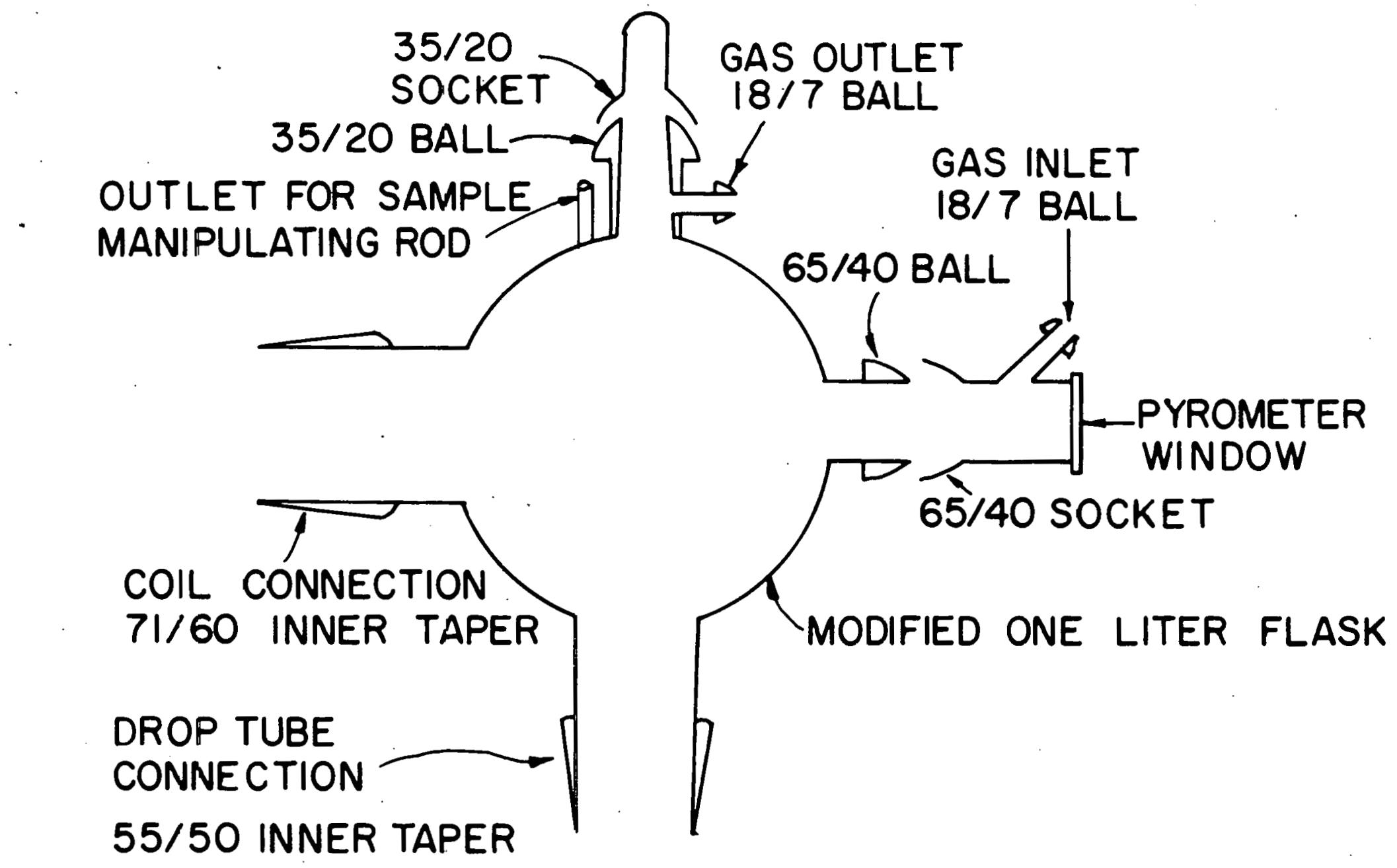

Figure 6. Levitation chamber. 
recorded on a $I$ and $N$ Speedomax $W$ Adjustable Range (AZAR) single point recorder. The pyrometer determines the brightness temperature of the sample by automatically adjusting the current passing through an internal standard lamp to match the sample being observed. The standard lamp current is converted to a millivolt reading and passed to the recorder.

The pyrometer operates over four temperature ranges which are $775{ }^{\circ} \mathrm{C}$ to $1225^{\circ} \mathrm{C}, 1075{ }^{\circ} \mathrm{C}$ to $1750{ }^{\circ} \mathrm{C}, 1500{ }^{\circ} \mathrm{C}$ to $2800{ }^{\circ} \mathrm{C}$ and $2000{ }^{\circ} \mathrm{C}$ to $5800{ }^{\circ} \mathrm{C}$. The accuracy of the pyrometer is governed by the calibration and stability of the standard lamp. The limits of error for this pyrometer are the same as for manual pyrometers. These limits are \pm 4 oC in the low range, $\pm 7^{\circ} \mathrm{C}$ in the medium range and $\pm 16^{\circ} \mathrm{C}$ in the high range. Uncertainty in N.B.S. calibration reports for $L$ and $N$ manually operated pyrometers are usually given as $\pm 4^{\circ} \mathrm{C}$ at $800{ }^{\circ} \mathrm{C}, \pm 3{ }^{\circ} \mathrm{C}$ at $1063^{\circ} \mathrm{C}$ and $\pm 8{ }^{\circ} \mathrm{C}$ at $2800{ }^{\circ} \mathrm{C}$.

The pyrometer resolution is given as $0.5{ }^{\circ} \mathrm{C}$ for a one second balance time at $1063^{\circ} \mathrm{C}$ with a one second response time. The filters on the pyrometer have an approximate passband of $350 \AA$ and an effective wavelength of approximately $0.645 \mu$.

Although calibration curves were furnished, several additional calibration checks were necessary. No recently acquired N.B.S. standard lamp was available, therefore a N.B.S. lamp acquired in 1963 was used. For comparative purposes, a manual pyrometer recently calibrated was used. The automatic and manual pyrometers were focused on the same location of the standard lamp filament. Temperature values were taken from $1050{ }^{\circ} \mathrm{C}$ to $1700^{\circ} \mathrm{C}$. Temperature values of the manual pyrometer were consistently $19{ }^{\circ} \mathrm{C}$ lower than the calibration temperature for the 
lamp. These results were not surprising as a dark residue could be seen on the inside surface of the N.B.S. lamp bulb.

The automatic pyrometer readings were $13{ }^{\circ} \mathrm{C}$ less at $1050{ }^{\circ} \mathrm{C}$ and $52{ }^{\circ} \mathrm{C}$ less at $1700{ }^{\circ} \mathrm{C}$ than the manual pyrometer readings. The variation in the above range was linear with respect to temperature.

A second calibration check consisted of taking temperature readings from both pyrometers while observing a levitated sample of liquid cerium. In this case, the automatic pyrometer readings were $43^{\circ} \mathrm{C}$ less at $1050{ }^{\circ} \mathrm{C}$ and $59^{\circ} \mathrm{C}$ less at $1700^{\circ} \mathrm{C}$ than the manual pyrometer readings. Again the variation was linear with respect to temperature. A linear pyrometer correction factor was calculated from both sets of data giving

$$
\mathrm{T}_{\mathrm{ac}}^{\prime}=(1.0422)\left(\mathrm{T}_{\mathrm{a}}^{\prime}\right)-13.87
$$

where $T_{a}^{\prime}$ is the apparent sample brightness temperature and ' $T_{a c}^{\prime}$ is the corrected apparent sample brightness temperature. The correction with respect to the two different test methods should be reliable. The greatest deviation from the correction factor occurred at the lower temperature values.

The pyrometer window located in the optical path between the levitated sample and the pyrometer was a thin piece of polished quartz glass. This factor was corrected for by Stretz (1) by inserting the window in the optical path of a ribbon filament lamp at a known temperature. 
EXPERIMENTAL PROCEDURE

The experimental procedure involved with levitation calorimetry may be divided into two sections. The initial setup involves the preparation of the system for runs and the actual runs. The major steps are listed below.

1. Construct a levitation coil which will levitate and melt a sample material. Individual coils were made from a $1 / 8$ inch diameter soft copper tube 24 inches in length. The construction is aided with various shaped articles to give the desired contour. For example, solenoid type coils were shaped around metal shafts of various diameters. Conical sections were shaped around objects with a desired taper angle, such as a glass funnel. Care must be taken to avoid introducing unnecessary bends in the coil configuration. The open ends of the coil must be clean to allow maximum cooling water flow. Comparisons should be made between designed coils and coils which have been used successful1y.

2. Install the coil and clamp the levitation chamber into place.

3. Test the new coil for sample levitation, melting and stability. Once the sample is levitated, stability is very important for uniform heating and accurate temperature values. Stability is accomplished by making a we11-defined neutral zone between the upper and lower segments of the coil. Generally, the larger the sample the more the stability problem will be apparent. Several coils may be needed to take data on a wide temperature range.

4. Weigh the empty receiving we11. 
5. Line the empty receiving well with protective foll and reweigh to determine the liner weight. A copper lining was used for copper sample calibration experiments. A tantalum liner was used for the cerium runs to avoid the possibility of the cerium sample and the copper lining forming an alloy. Tantalum liners were found by Stretz (1) to be suitable when working with lanthanum, praseodymium, yttrium and neodymium.

After the above steps have been completed, the remainder of the procedure is associated with all actual runs.

1. Start the constant temperature bath and a11 the support equipment. The temperature of the bath must be stable before runs are made.

2. Weigh the receiving wel1, liner and old sample, if any. Determine the correction factor to be applied to the calorimeter constant.

3. Insert the we11 into the block and place the block cover gate over the wel1. After assembling the calorimeter, place it in the isothermal bath.

4. Raise the isothermal bath up to the levitation chamber and assemble the unit. Open the block cover gate and close the radiation gate.

5. Begin purging the system with inert gas at a helium-argon composition desired for the levitation run. Check the system for leaks.

6. After $1 / 2$ hour, remove the sample to be levitated from vacuum storage. Place the sample on the glass manipulating rod positioned 
Inside the lower section of the levitation coil. Continue purging for approximately 2 hours.

7. Prepare levitation system for operation. (Warm up the generator and related equipment and turn on cooling water.)

8. Prealign the pyrometer so only minor adjustments wil1 be necessary.

9. Turn quartz thermometer to monitor calorimeter temperature at $0.0001{ }^{\circ} \mathrm{C}$ resolution and switch on digital recorder. The time interval between readings wil1 be approximately 10 seconds. An exact time interval of 10 seconds is not necessary. The time interval should, however, remain constant between calorimeter temperature readings for the duration of one run.

10. Eight minutes later, turn on the levitation power and maintain stable sample levitation by altering the power. Realign the pyrometer at this time.

11. When constant temperature is apparent, open the radiation gate and drop the sample by use of the sample drop mechanism.

12. Immediately close the block cover gate, then the radiation gate. Mark the digital temperature readout for the exact drop time.

13. Shut down the generator and pyrometer.

14. Take readings of the calorimeter temperature with respect to time until the $\mathrm{dT} / \mathrm{dt}$ valve has been constant for at least 5 minutes.

15. Shut off purge gas flow and cooling water supplies. Break down the system removing the calorimeter for final weighings and inspection.

16. Dry and disassemble the calorimeter. 
17. Inspect the calorimeter for sample contact and splash.

18. Weigh the well to determine the weight of the dropped sample. This is determined after the drop since some of the sample will vaporize during levitation.

To make further runs reassemble the calorimeter with the well that has been previously weighed. At this time the block should be cooled with liquid nitrogen to approximate $1 \mathrm{y} 18^{\circ} \mathrm{C}$. This will allow the temperature of the block to rise to the desired level after the $2-1 / 2$ hours of purge time if the bath is maintained at approximately $25{ }^{\circ} \mathrm{C}$. At this point, procedure 2 of the actual run sequence has begun .

The remainder of the procedure involves the computer data reduction routines TEMC, CAL, and COR2 as used by Stretz (1). The operation of these routines is explained in the calculation section of this thesis. 
CALCULATIONS

The following section will be devoted to explaining the raw data reduction routines from a series of experimental trials on any given levitated sample. These calculations follow the procedures set forth by Bonnel1 (2) as presented by Stretz (1). The only deviation from that presented by Stretz (1) will be the added pyrometer correction. factor explained in the equipment section of this thesis.

The primary raw data from the levitation operation consisted of the apparent brightness temperature, $\mathrm{T}_{\mathrm{a}}^{\prime}$, of the levitated sample and the temperature versus time data for the calorimeter block. The heat content, heat capacity, entropy, enthalpy function and free energy function were calculated according to the raw data reduction routines with the aid of supplementary data. These reduction routines include the conversion of the apparent brightness temperature to a true sample temperature, the correction of the calorimeter constant, the evaluation of the corrected temperature rise of the block, and the correction to the experimental heat content for the energy lost by radiation and convection during the sample drop. Finally the heat capacity is calculated from the heat content values and the thermodynamic functions are calculated accordingly. Details are given in the following sections.

True samp le 'l'emperature

The brightness temperature is defined as the temperature at which a perfect radiator would radiate energy with the same intensity as the sample. In order to obtain a true temperature from the brightness 
temperature, a correction for nonblackbody behavior has to be made. The correction was made using the following equation.

$$
T=\frac{1}{\frac{\lambda}{C_{2}} \ln \varepsilon_{N \lambda}+\frac{1}{T_{a}}}
$$

In this equation $T$ is the true temperature, $T_{a}$ is the brightness temperature, $\lambda$ is the wavelength of the pyrometer, $C_{2}$ is Plank's second radiation constant and $\epsilon_{\mathrm{N} \lambda}$ is the normal spectral emittance of the sample material. Emittance by definition is the ratio of the emitted radiant flux per unit area by a body to that of a blackbody radiator at the same conditions. In comparison, the emissivity ratio is the same as for emittance except that the body in question is opaque and has a smooth, polished surface. Emittance is then an extensive property while emissivity is an intensive property. Theory and derivation of equation 19 is cited in Stretz $(1,20)$ and in Stretz and Bautista (21).

The brightness temperature, $\mathrm{T}_{a}$, was obtained from the corrected apparent brightness temperature, $\mathrm{T}_{\mathrm{ca}}^{\prime}$. The corrected apparent brightness temperature was found according to the correction as discussed in the equipment section: This correction is

$$
T_{c a}^{\prime}=(1.0422)\left(T_{a}^{\prime}\right)-13.87
$$

where $T_{a}^{\prime}$ is the apparent brightness temperature. The brightness temperature was then obtained by correcting for the absorbance of the optical system between the sample and the pyrometer. The main source of this absorbance was the quartz window located on the levitation chamber. The absorbance effects were determined from 


$$
\mathrm{T}_{\mathrm{a}}=\frac{1}{\mathrm{~K}_{\mathrm{abs}}+\frac{1}{\mathrm{~T}_{c a}^{\prime}}}
$$

where $\mathrm{K}_{\mathrm{abs}}$ is the absorbance constant. The constant was determined as described in the equipment section.

The error in determining the apparent brightness temperature is dependent on the accuracy of the pyrometer readings. The true sample temperature is relatively insensitive to spectral emittance or absorbance constant errors. At $2000{ }^{\circ} \mathrm{K}$ errors of about $\pm 5 \%$ in spectral emittance or absorbance constant result in errors of less than $\pm 0.5 \%$. in true sample temperature.

\section{Corrected Block Temperature Rise}

The apparent block temperature rise is the difference in the temperature of the calorimeter block before and after the main period of temperature change. This apparent temperature rise must be corrected for energy losses to the surrounding purge gas. The evaluation of this heat loss was performed according to the method presented in the theory section.

The thermal leakage constant, $k$, from equation 8 was evaluated by correlating the initial and final period values of temperature versus time relations with the associated value of $\mathrm{dT} / \mathrm{dt}$ at the midtime. The corrected equation was then numerically integrated by the trapezoidal rule. The estimated truncation error for this type of integration was significantly less than the accuracy by which the quartz thermometer 
could measure the temperature rise. Speciffc detalls of this correction are given by stretz (1).

\section{Calorimeter Constant}

An actual calorimeter constant was not determined in this work. This calibration was not necessary due to the results of the copper calibration experiments and the calibration previously performed by Stretz (1). The electrical calibration resulted in a block constant of 472.122 cal. per degree. This value was corrected according to the following equation

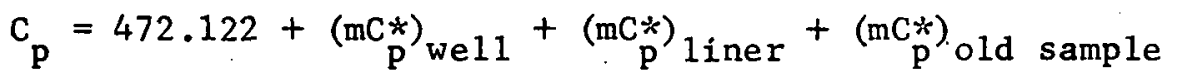

In this form $\mathrm{C}_{\mathrm{p}}$ is the corrected block constant in cal per degree, $m$ is mass in grams and $\mathrm{C}_{\mathrm{p}}^{*}$ is heat capacity in cal per degree per gram.

\section{Experimenta1 Heat Capacity Calculation}

The experimental heat content of a specific sample is given as follows in cal per mole

$$
\mathrm{H}_{\mathrm{T}}-\mathrm{H}_{298.15}(\exp )=\frac{\mathrm{MC}_{\mathrm{p}} \Delta \mathrm{T}}{\mathrm{m}}
$$

In this form $M$ is the molecular weight of cerium, $\mathrm{C}_{\mathrm{p}}$ is the calorimeter constant, $\Delta \mathrm{T}$ is the corrected temperature risc of the calorimeter block and $m$ is the mass of the cerium sample. 
A correction is applied to this heat content in the form of radiative and convective energy losses, while the sample fell from the coil to the block.

The convective heat loss was treated as a stationary sphere in a flowing inert gas stream. The composition of the purge gas is an important part of this calculation. Pure helium removes heat from the sample at a much quicker rate than pure argon. This is illustrated by Stretz (1) for the heat loss from yttrium samples.

The equation used for this heat transfer was

$$
\Delta H_{c}^{*}=\int_{0}^{t} h_{m} A \Delta T d t
$$

where $\Delta_{c}^{*}$ is the convective heat loss in calories, $h_{m}$ is the mean heat transfer coefficient, $A$ is the surface area of the sample, $\Delta T$ is the temperature difference between the sample and the bulk purge gas and $t_{d}$ is the time involved in the actual drop.

The radiative heat loss was treated in much the same fashion, using the Stefan-Boltzman law.

$$
\mathrm{dH}_{\mathrm{r}}^{*}=\epsilon_{\mathrm{HT}_{\mathrm{S}}} \mathrm{A}_{\mathrm{s}} \sigma \mathrm{T}^{4} \mathrm{dt}
$$

In this form, $\mathrm{dH}_{\mathrm{r}}^{*}$ is the differential radiative heat loss, $\epsilon_{\mathrm{HT}}$ is the hemispherical total emittance of the sample, $A_{s}$ is the surface area of the sample, $\sigma$ is the Stefan-Boltzman constant, $T$ is the sample temperature and $\mathrm{dt}$ is the differential time or drop time.

The application of the radiative heat loss required the use of the sample heat capacity. To combine the radiative and convective heat loss required an 1teration procedure involving the experimental heat 
content values. This procedure included the fitting of a straight line to the final heat content values. The slope represented the heat capacity of the material. Specific details of the iteration process are given by Stretz (1).

The value of the hemispherical total emittance, $\varepsilon_{\mathrm{HT}}$, for cerium is the only primary source of error in this calculation. This value is not available for cerium. The value of the normal. spectral emittance had been found by Moscowitz et a1. (22) to be $0.309 \pm 0.02$. This value was measured under vacuum conditions for the temperature range $1100{ }^{\circ} \mathrm{C}$ to $1500{ }^{\circ} \mathrm{C}$. The accuracy of this value is verified by more recent work involving the determination of normal spectral emittance values for cerium up to $1800^{\circ} \mathrm{C}$ using an inert atmosphere. The value was found to be 0.320. (T. King, D. N. Baria and R. G. Bautista, Iowa State University, Ames, Iowa, unpublished data, 1973.)

According to the procedure outlined by Baria and Bautista (23), the value of the bemispherical spectral emittance, $\varepsilon_{\mathrm{H} \lambda}$, may be approximated by

$$
\epsilon_{\mathrm{H} \lambda}=(1.07)\left(\varepsilon_{\mathrm{N} \lambda}\right)
$$

and the hemispherical total emittance, $\epsilon_{\mathrm{HT}}$, may be approximated by

$$
\epsilon_{\mathrm{HT}}=(1.25)\left(\varepsilon_{\mathrm{H} \lambda}\right)
$$

Errors in the estimate of the hemispherical total emittance values are discussed by Stretz (1) relative to his work with yttrium. Possible errors concerning these values relative to cerium are discussed in the results section. 
Thermodynamic Functions

The corrected values of the heat content and heat capacity are relative to the standard reference state of $298.15{ }^{\circ} \mathrm{K}$ and 1 atm pressure. The entropy is found from the following integral where $s_{0}^{0}=0$.

$$
\mathrm{s}_{\mathrm{T}}^{\mathrm{o}}-\mathrm{s}_{\mathrm{o}}^{\mathrm{o}}=\int_{0}^{\mathrm{T}} \frac{\mathrm{c}}{\mathrm{T}} \mathrm{dT} .
$$

This integral was split into 5 sections giving

$$
\mathrm{S}_{\mathrm{T}}^{\mathrm{o}}-\mathrm{s}_{\mathrm{o}}^{\mathrm{o}}=\int_{0}^{\mathrm{T}} \frac{\mathrm{C}_{\mathrm{p}}}{\mathrm{T}} \mathrm{dT}+\Delta \mathrm{S}_{\mathrm{t}}+\int_{\mathrm{T}_{\mathrm{t}}}^{\mathrm{T}} \frac{\mathrm{C}_{\mathrm{p}}}{\mathrm{T}} \mathrm{dT}+\Delta \mathrm{S}_{\mathrm{f}}+\int_{\mathrm{T}_{\mathrm{m}}}^{\mathrm{T}} \frac{\mathrm{C}_{\mathrm{p}}}{\mathrm{T}} \mathrm{dT},
$$

where $T_{t}$ is the $\alpha-\beta$ transition temperature of solid cerium, $\Delta S_{t}$ is the entropy of transition, $T_{m}$ is the melting temperature and $\Delta S_{f}$ is the entropy of fusion for cerium. The first 4 values were taken from Mckeown (3). The value of the third integral is taken from this experimental evaluation as presented in the results section of this thesis.

The enthalpy function, $\left(\mathrm{H}_{\mathrm{T}}^{\mathrm{O}}-\mathrm{H}_{298.15}^{\mathrm{O}}\right) / \mathrm{T}$, was found according to the following relation

$$
\frac{\left(\mathrm{H}_{\mathrm{T}}^{\mathrm{O}}-\mathrm{H}_{298.15}^{\mathrm{O}}\right)}{\mathrm{T}}=\frac{1}{\mathrm{~T}}\left[\int_{298.15}^{\mathrm{T}_{\mathrm{t}}} \mathrm{C}_{\mathrm{p}} \mathrm{dT}+\Delta \mathrm{H}_{\mathrm{t}}+\int_{\mathrm{T}_{\mathrm{t}}}^{\mathrm{T}_{\mathrm{m}}} \mathrm{C}_{\mathrm{p}} \mathrm{dT}+\Delta \mathrm{H}_{\mathrm{f}}+\int_{\mathrm{T}_{\mathrm{m}}}^{\mathrm{T}} \mathrm{C}_{\mathrm{p}} \mathrm{dT}\right]
$$

where $\Delta \mathrm{H}_{t}$ is the heat of transition and $\Delta \mathrm{H}_{f}$ is the heat of fusion. The temperatures are the same as those in the entropy equation. The first four parts of this equation were taken from McKeown (3) and the third integral was evaluated as presented in the results section of this thesis. 
The free energy function, $-\left(\mathrm{F}_{\mathrm{T}}^{\circ}-\mathrm{H}_{298.15}^{\circ}\right) / \mathrm{T}$, was found as follows.

$$
-\frac{\left(F_{T}^{\circ}-H_{298.15}^{\circ}\right)}{T}=S_{T}^{\circ}-S_{o}^{\circ}-\frac{\left(H_{T}^{\circ}-H_{298.15}^{\circ}\right)}{T}
$$

This is derived by adding the enthalpy function, $\left(\mathrm{H}_{\mathrm{T}}^{\mathrm{O}}-\mathrm{H}_{298.15}^{\mathrm{O}}\right) / \mathrm{T}$, to both sides of the free energy function as shown below.

$$
\frac{\mathrm{F}_{\mathrm{T}}^{\mathrm{o}}-\mathrm{H}_{\mathrm{T}}^{\circ}}{\mathrm{T}}+\frac{\mathrm{H}_{\mathrm{T}}^{\mathrm{O}}-\mathrm{H}_{298.15}^{\circ}}{\mathrm{T}}=-\mathrm{S}_{\mathrm{T}}^{\mathrm{o}}+\frac{\mathrm{H}_{\mathrm{T}}^{\circ}-\mathrm{H}_{298.15}^{\circ}}{\mathrm{T}}
$$

Simplifying yields the following equation which is equivalent to equation 30 .

$$
\frac{\mathrm{F}_{\mathrm{T}}^{\mathrm{O}}-\mathrm{H}_{298.15}^{\mathrm{O}}}{\mathrm{T}}=-\mathrm{S}_{\mathrm{T}}^{\mathrm{O}}+\frac{\mathrm{H}_{\mathrm{T}}^{\mathrm{O}}-\mathrm{H}_{298.15}^{\circ}}{\mathrm{T}}
$$

Al1 the rmodynamic functions are in units of cal per mole per degree Kelvin. 
RESULTS AND DISCUSSION

High purity samples of cerium were prepared (24) within the Ames Laboratory of the U.S. Atomic Energy Commission. These samples were swaged from cerium stock into $1 / 4$ inch diameter cylinders, $1 / 4 \mathrm{inch}$ and $3 / 8$ inch in length. The samples were stored under vacuum until needed, at which time they were recut to obtain specific sample weights, electropolished and again stored under vacuum. This procedure was necessary to avold rapid oxidation. Electropolished samples could be kept 2-4 days under vacuum without the oxide forming. The cerium used was approximately $99.98 \%$ pure. A complete analysis of impurities before levitation is given in Table 1.

Prior to beginning the work on cerium, the heat content of liquid copper was measured in order to check the previous calibration made by Stretz (1). Copper is used as the calibration standard since it is easy to levitate, resists oxidation and the heat content of the liquid phase been determined to $700{ }^{\circ} \mathrm{K}$ above the melting point $\left(1358{ }^{\circ} \mathrm{K}\right)$, by several investigators at different laboratories. Furthermore, a wide range of temperatures may easily be obtained, as the levitation of copper only requires one basic coil design up to an estimated temperature of $2200{ }^{\circ} \mathrm{K}$.

Calibration Evaluation

Seven runs on samples of $99.999 \%$ pure copper were made over a temperature range from $1700{ }^{\circ} \mathrm{K}$ to $2000 \mathrm{o}_{\mathrm{K}}$. Data from these runs was treated as described in the calculation section. The value of the 
Table 1. Impurities of cerlum metal samples before levitation in ppm atomic

\begin{tabular}{|c|c|c|c|c|}
\hline $\mathrm{Be}<0.003$ & $B<0.01$ & $\mathrm{Na}=0.04$ & $\mathrm{Mg}<0.01$ & $\mathrm{~A} 1=0.02$ \\
\hline$S i=0.079$ & $P=0.02$ & $s<1$ & $\mathrm{Cl}=0.7$ & $\mathrm{~K}=0.03$ \\
\hline $\mathrm{Ca}=0.2$ & $\mathrm{Ti}=0.21$ & $V=0.014$ & $\mathrm{Cr}=3.4$ & $M n=0.75$ \\
\hline $\mathrm{Fe}=13$ & $C o=0.04$ & $\mathrm{Ni}=3$ & $\mathrm{Cu}=2$ & $\mathrm{zn}=0.08$ \\
\hline $\mathrm{Ga}<0.02$ & $\mathrm{Ge}<0.1$ & $A s=0.02$ & $\mathrm{se}<0.1$ & $\mathrm{Kr}<0.5$ \\
\hline $\mathrm{Rb}<0.8$ & $\mathrm{Sr}<0.4$ & $\mathrm{Zr}<0.2$ & $\mathrm{Nb}<20$ & Mo $<0.2$ \\
\hline $\mathbf{R u}<0.09$ & $\mathrm{Rh}<0.02$ & $\mathrm{Pd}<0.05$ & $\mathrm{Ag}<0.009$ & $\mathrm{Cd}<0.02$ \\
\hline In $<0.009$ & $\mathrm{Sn}<0.003$ & $\mathrm{Sb}<0.01$ & $\mathrm{Te}<0.02$ & $I<0.01$ \\
\hline Cs $<0.001$ & $\mathrm{Ba}<0.3$ & $\mathrm{HEF}<0.3$ & $\mathrm{Ta}=7.0$ & $W<0.4$ \\
\hline $\operatorname{Re}<0.1$ & $0 \mathrm{~s}<0.2$ & $\operatorname{Ir}<0.08$ & $\mathrm{Pt}=4.0$ & $\mathrm{Au}<0.02$ \\
\hline $\mathrm{Hg}<0.02$ & $\mathrm{~T} 1<0.02$ & $\mathrm{~Pb}<0.05$ & $\mathrm{Bi}<0.01$ & Th $<0.2$ \\
\hline $\mathrm{U}=0.3$ & $\mathrm{Sc}=0.3$ & $Y=10$ & $\mathrm{La}=9$ & $\operatorname{Pr}<1$ \\
\hline $\mathrm{Nd}=4$ & $\mathrm{Sm}<0.4$ & $\mathrm{Eu}<0.05$ & $\mathrm{Gd}=6$ & $\mathrm{~Tb}<1$ \\
\hline$D y=1$ & Ho $<1$ & $\operatorname{Er}=5$ & $\operatorname{Tm}<0.06$ & $\mathrm{Yb}<0.3$ \\
\hline$L u=9$ & $\begin{array}{l}0^{\mathrm{a}}=44 \\
\mathrm{o}^{\mathrm{b}}=120\end{array}$ & $\begin{array}{l}\mathrm{N}^{a}=12 \\
\mathrm{~N}^{\mathrm{b}}=39\end{array}$ & $\begin{array}{l}\mathrm{H}^{\mathrm{a}}=2 \\
\mathrm{H}^{\mathrm{b}}=10\end{array}$ & $c^{a}=4$ \\
\hline
\end{tabular}

aalues for this impurity in ppm by weight.

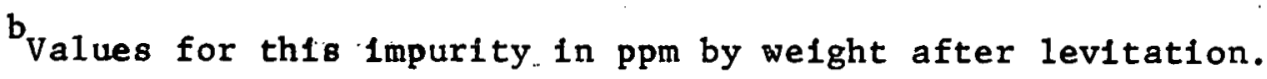


hemispherical total emittance, $\epsilon_{\mathrm{HT}}$, was 0.1 and the liquid density was taken to be 8.03 gram per $\mathrm{cm}^{3}$. The average percent deviation of the experimental values from the linear fit was $0.27 \%$. The equation obtained from the linear fit for the heat content of liquid copper as a function of temperature was

$$
\begin{aligned}
& \mathrm{H}_{\mathrm{T}}-\mathrm{H}_{298.15}=8.137(\mathrm{~T}-1358)+10130 \mathrm{cal} / \mathrm{mole} \\
& \text { for } 1700 \mathrm{o}_{\mathrm{K}}<\mathrm{T}<2000 \mathrm{o}_{\mathrm{K}}
\end{aligned}
$$

where 8.137 is the experimental heat capacity in cal per mole per. degree. A comparison of these results with the data presented by Kelley (8), Bonnell (2), Stretz (1) and Stephens (25) are given in Table 2 and Figure 7 . The agreement with the literature values is excellent and verifies the previous calibration.

\section{Cerium Evaluation}

\section{Cerium levitation coils}

Runs on cerium samples were made with three different coil designs including several variations from the standard designs. These different destgns are 11luserated in f'igure 8.

Solenoid coil design A consisted of 2 turns in the upper section wound on a $3 / 4$ inch form and 3 turns in the lower section wound on a $3 / 8$ inch form. The neutral zone gap was approximately $3 / 8$ inch wide. This coil worked particularly we11 in establishing the heat content of cerium between $15500^{\circ}$ and $2000{ }^{\circ}$. The results of these evaluations were consistent and provided a basis for the high and low temperature experiments. 
Table 2. Ilquid copper evaluations and comparative literature values

\begin{tabular}{|c|c|c|c|c|c|c|c|c|c|}
\hline $\mathrm{T}{ }^{\circ} \mathrm{K}$ & $\begin{array}{c}\text { This work } \\
\Delta \mathrm{H} \\
\text { cal } / \mathrm{mole}\end{array}$ & $\begin{array}{c}\text { Stretza } \\
\Delta H \\
\text { cal/mole }\end{array}$ & $\begin{array}{c}\text { Dev. } \\
\%\end{array}$ & $\begin{array}{c}\text { Bonne } 11^{b} \\
\Delta \mathrm{H} \\
\mathrm{ca} 1 / \mathrm{mole}\end{array}$ & $\begin{array}{c}\text { Dev. } \\
\%\end{array}$ & $\begin{array}{c}\text { Stephens }^{c} \\
\Delta \mathrm{H} \\
\mathrm{ca} 1 / \mathrm{mole}\end{array}$ & $\begin{array}{c}\text { Dev. } \\
\%\end{array}$ & $\begin{array}{c}\mathrm{Kelley}^{\mathrm{d}} \\
\Delta \mathrm{H} \\
\mathrm{cal} / \mathrm{mole}\end{array}$ & $\underset{\%}{\text { Dev. }}$ \\
\hline 1700 & 12913 & 12878 & -0.27 & 13134 & 1.7 & 13116 & 1.6 & $(12730)$ & -1.4 \\
\hline 1800 & 13727 & 13654 & -0.53 & 13961 & 1.7 & 13916 & 1.4 & $(13480)$ & -1.8 \\
\hline 1900 & 14540 & 14429 & -0.76 & $(14788)$ & 1.7 & 14716 & 1.2 & $(14230)$ & -2.1 \\
\hline 2000 & 15354 & 15204 & -0.98 & (15615) & 1.7 & 15516 & 1.1 & $(14980)$ & -2.4 \\
\hline \multicolumn{10}{|c|}{ 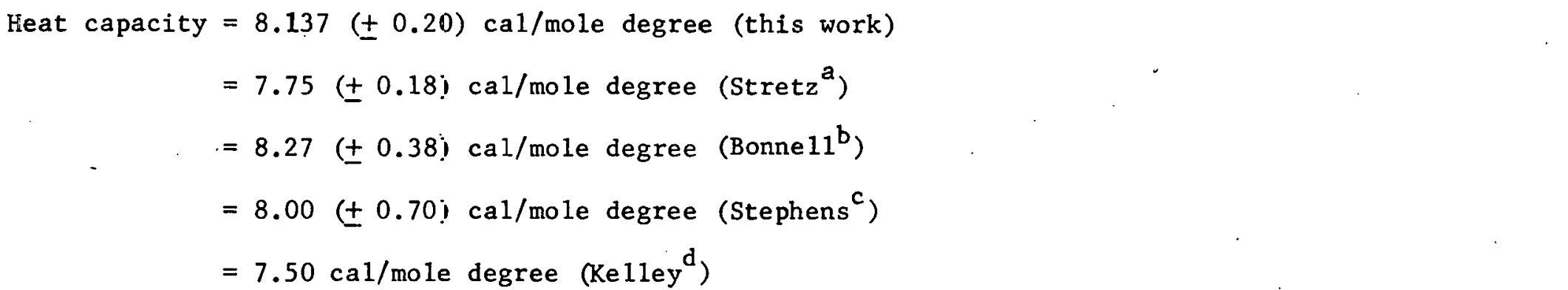 } \\
\hline
\end{tabular}

\footnotetext{
${ }^{a}$ Reference (1).

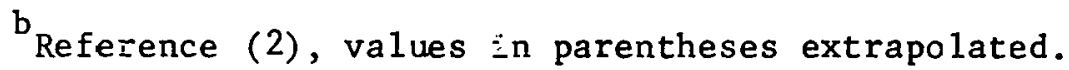

$c_{\text {Reference (25). }}$.

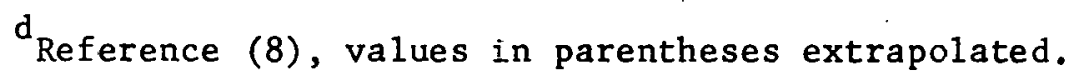




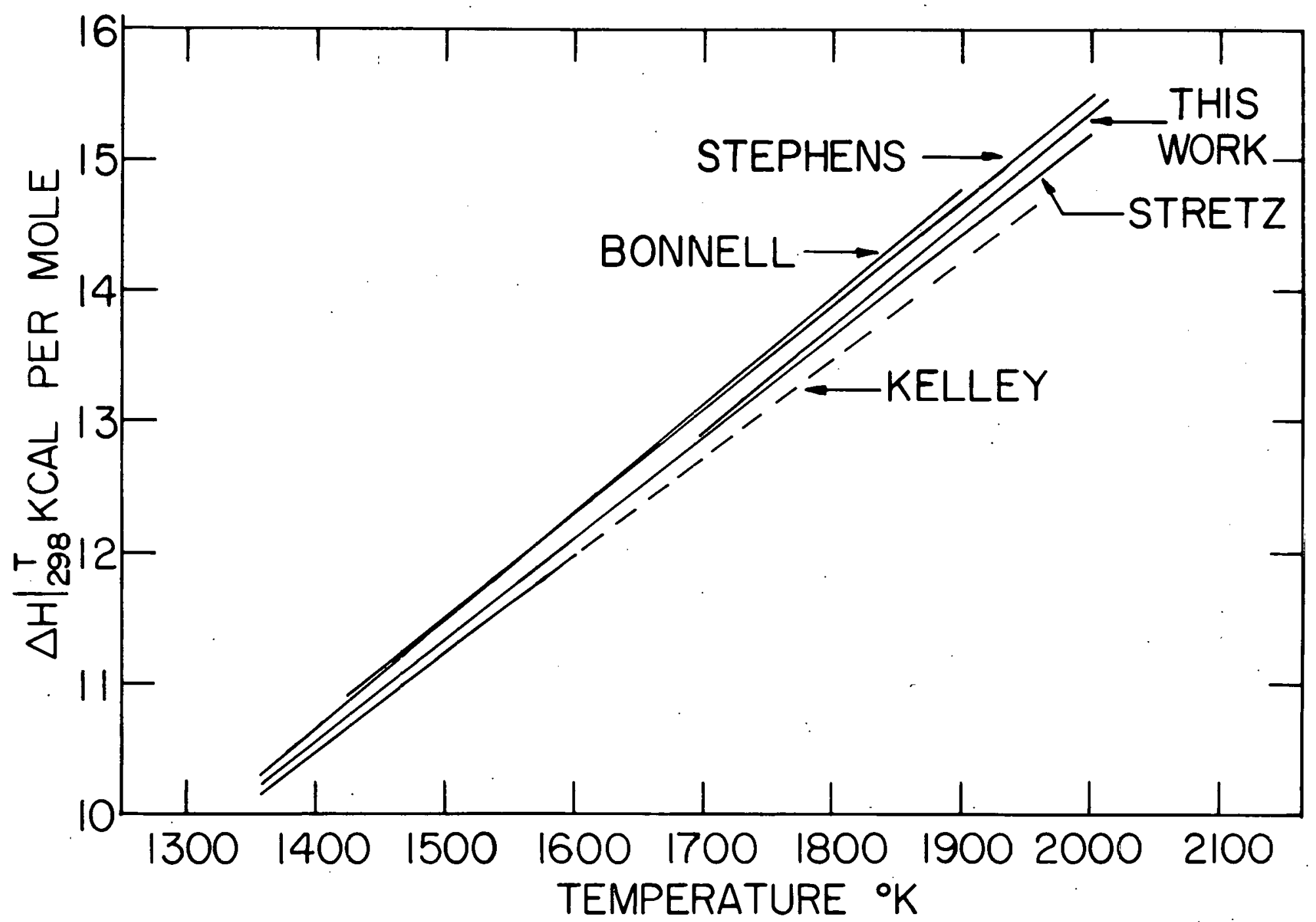

f

Figure 7. Experimental liquid copper heat content values and comparative literature values. 


\section{SOLENOID}

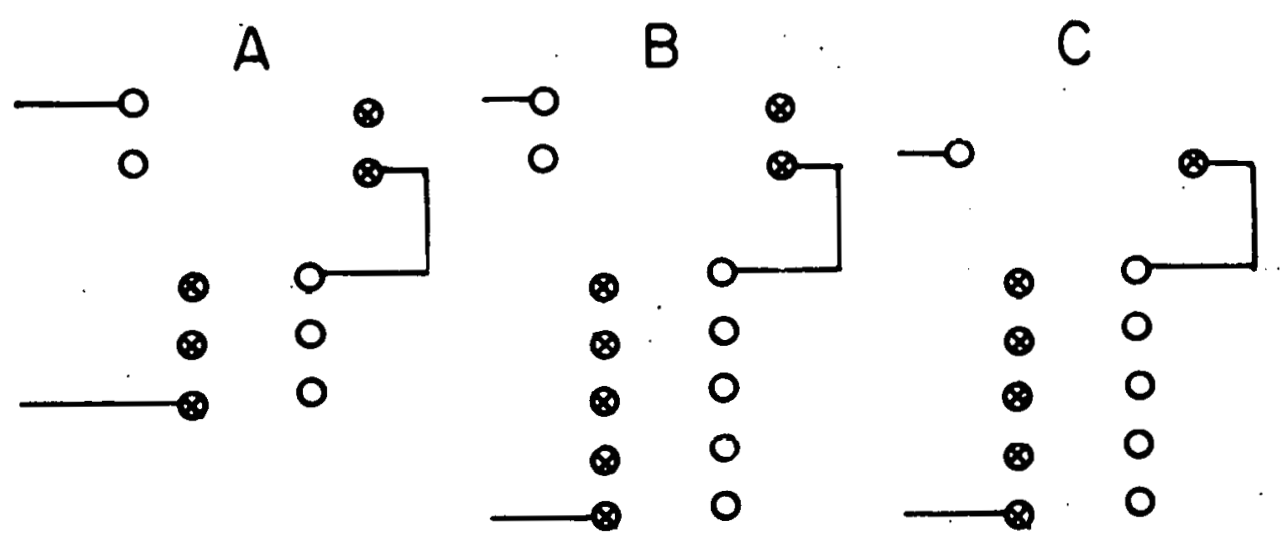

CONICAL

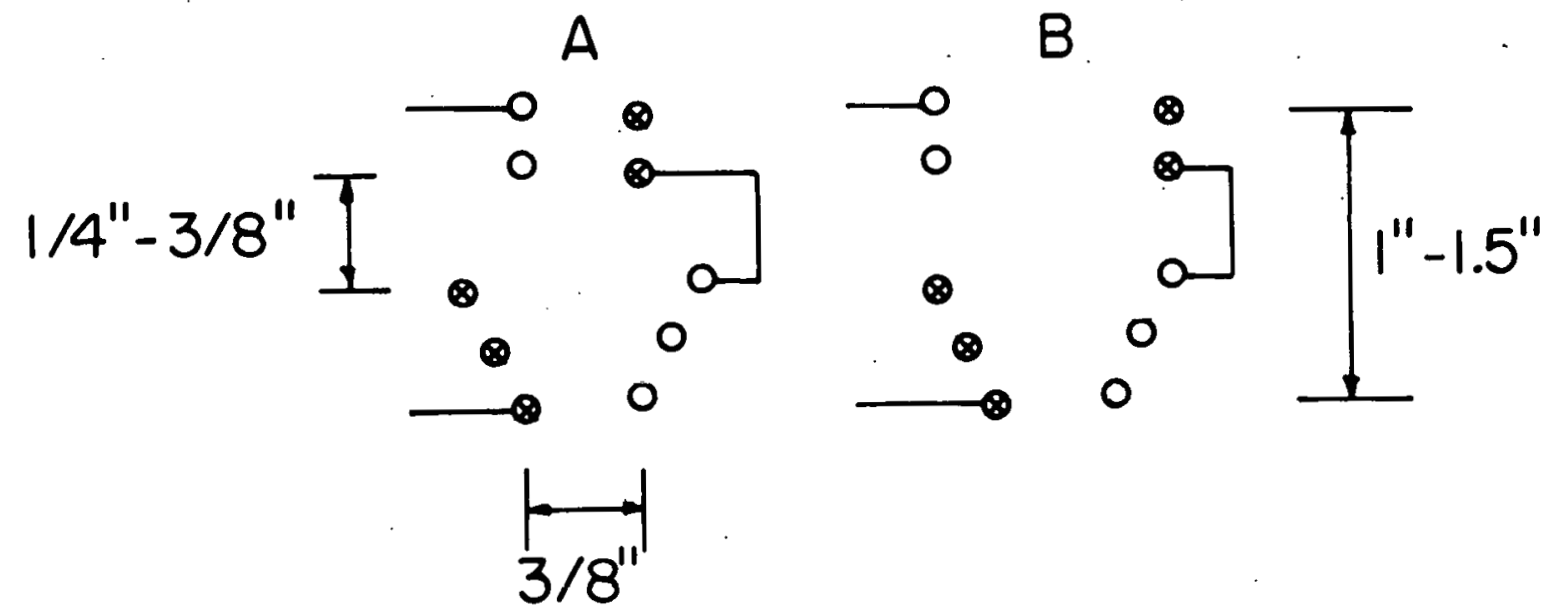

REVERSE CONICAL

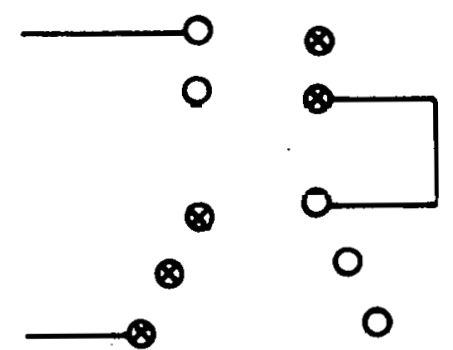

Figure 8. Levitation colls used for liquid cerium analysis. 
In an effort to obtain lower temperature heat content values, the reverse conical coil was used. It consisted of 2 turns in the upper section wound on a $3 / 8$ inch form and 3 turns in the lower section wound on a $30^{\circ}$ taper. The gap between the upper and lower sections was adjusted from $1 / 4$ to $3 / 8$ inch depending on the weight of the sample. This coil yielded poor results.. This can be attributed to poor mixing within the sample and severe interference directed into the temperature measuring equipment. The results for this coil indicated that the temperature values were approximately $150^{\circ}$ lower than what the previous results indicated. This coil was considered ineffective and abandoned. Solenoid coil design $B$ was used in place of the reverse conical. design in order to maintain maximum lift while reducing the power applied to the induction heating. This particular design has 2 upper section turns wound on a $3 / 4$ inch form with 5 lower section turns wound on a $3 / 8$ inch form. The neutral zone was adjusted from $1 / 4$ to $3 / 8$ inch depending on sample size. The structure of the solenoid coil $\mathrm{C}$ is very similar in that only one turn exists in the upper section. Solenoid coils $B$ and $C$ appeared to have nearly the same characteristics except that the stability of samples appeared to be the best in coil $\mathrm{B}$. Solenoid coil B was used successfully in conjunction with solenoid coil A. The first extended the temperature range to a value of $1400{ }^{\circ} \mathrm{K}$ while overlapping the midrange temperature values to $1600{ }^{\circ} \mathrm{K}$. Heat content values obtained from the use of solenoid coil $\mathrm{A}$ below $1550^{\circ} \mathrm{K}$ appear to verify results obtained by solenoid levitation coil B. The results obtained for each coil are indicated in Figures 9 and 10. Heat content values labeled with a circle, "o", were taken from 


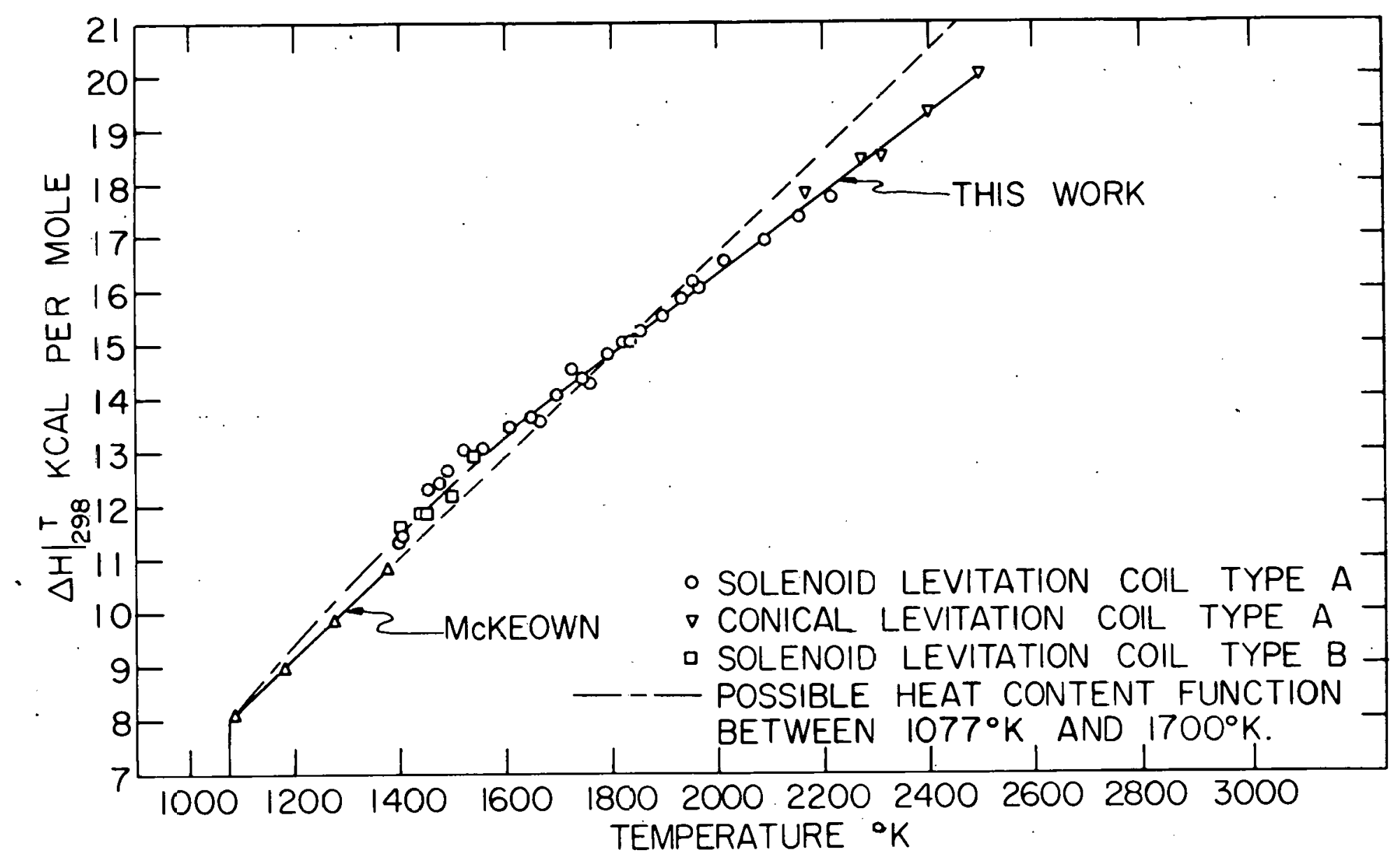

Figure 9. Experimental heat content values of liquid cerium from the melting point (1077 $\left.{ }^{\circ} \mathrm{K}\right)$ to $2500^{\circ} \mathrm{K}$. 


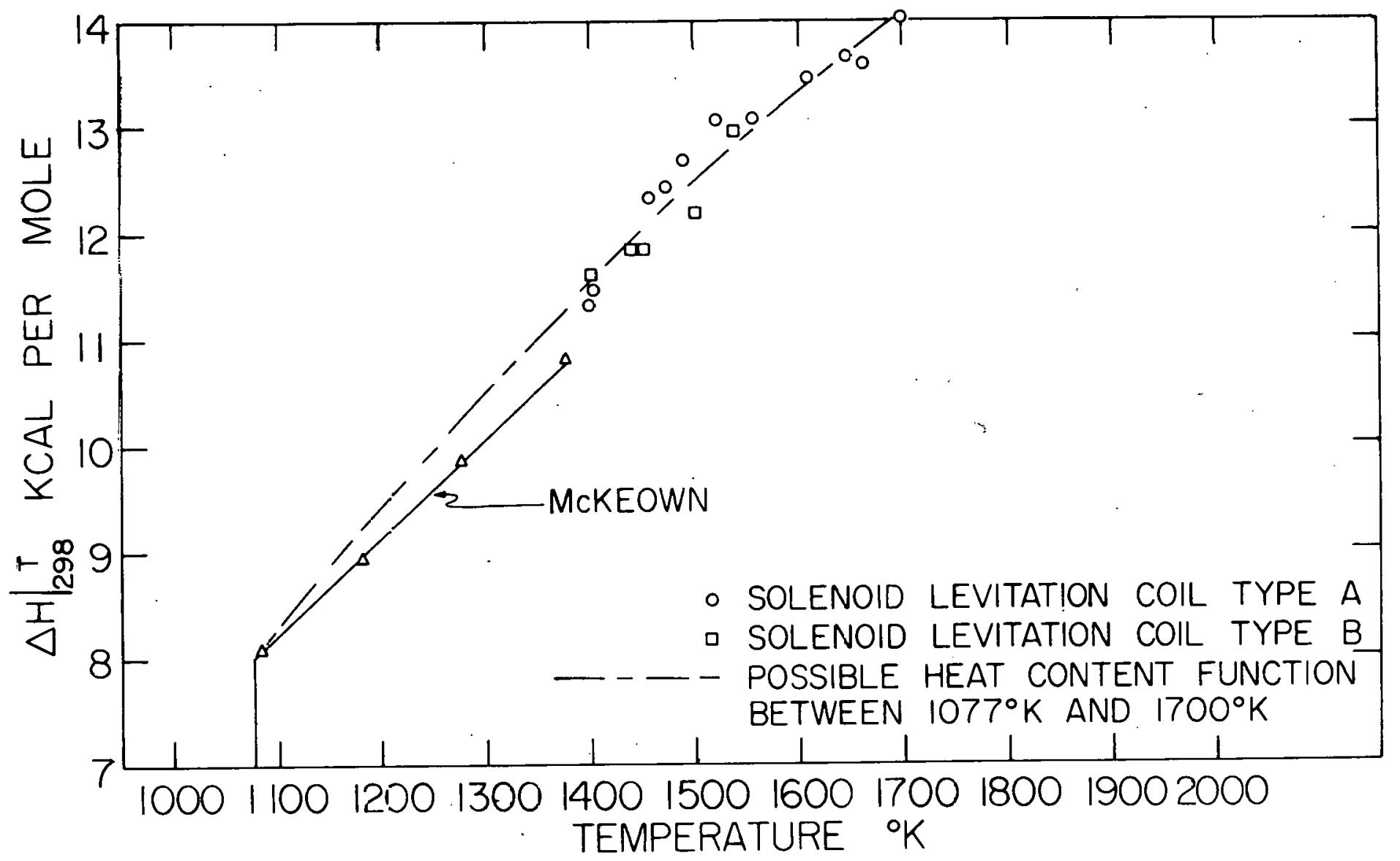

Figure 10. Experimental heat content values of liquid cerium between $1077 \mathrm{o}_{\mathrm{K}}$ and $17000_{\mathrm{K}}$. 
experiments using solenoid coll type A. Experiments with solenoid coil type $B$ are labeled with a square, ' $\square$ '.

The combined heat content values of solenoid coils $A$ and $B$ show a curving trend to the data below $1700 \mathrm{o}_{\mathrm{K}}$. These points are evaluated separately because of the indicated curvature. Experiments above $1700{ }^{\circ} \mathrm{K}$ are linear with temperature as shown in Figure 9.

Heat content values below $1400{ }^{\circ}$ were not experimentally determined due to the inability to levitate a sample while keeping the induction to a minimum. Lower temperatures may be reached but the samples must be decreased in size to less than 0.5 grams. The possibility for errors with the small samples became apparent by inconsistent heat content values, while sample temperatures were not lowered enough to merit further work. Figures 9 and 10 indicate the scattering of data below $1700{ }^{\circ}$.

Conical coils A and B are very similar in that the lower section consists of 3 turns wound on a $30^{\circ}$ taper. Coil A has 2 turns in the upper section wound on a $3 / 8$ inch form while coil B has 2 turns wound on a $3 / 4$ inch form. No detectable difference existed between the two concerning levitation melting quallties. Coll A was used to obtain high temperature heat content values from $2150{ }^{\circ} \mathrm{K}$ to $25000_{\mathrm{K}}$ using samples varying in size from 1.0 to 1.8 grams. Experiments involving conical coil type $A$ are shown in Figure 9 as inverted triangles, ' $\nabla$ '. The results of runs with this coil were verified by making a run below $2200{ }^{\circ} \mathrm{K}$. In this way experimentally determined heat content values could be compared to results obtained with an alternate coil design. No unusual conditions existed at $2500{ }^{\circ} \mathrm{K}$ except for the intense white light 
and a considerable temperature rise in the purge gas outlet. No experimental runs were attempted above this temperature due to the increased vapor pressure of the sample.

From these results, a portion of the guesswork in coil designs has been eliminated. The purge gas composition, sample weight, coil neutral zone width and shape of the lower coil sections seemed to generate the variables associated with obtaining different temperatures. Consequently the power to the coil is not critical except during the initial levitation process. The power to the coil is most critical at this time to obtain levitation before me1ting, due to the low melting temperature of cerium. Once levitated, the sample weight and neutral zone width governed the position of the sample yielding a specific temperature for those conditions. This combined with the heat removed from the sample by the purge gas and the structure of the lower coil section dictated the ability to obtain a wide range of sample temperatures.

\section{Cerium results}

Results of the work with cerium are tabulated in Table 3 . The linear fit to the corrected heat contents gave

$$
\begin{aligned}
& \mathrm{H}_{\mathrm{T}}-\mathrm{H}_{298.15}=[7.42 \pm 0.14]\left(\mathrm{T}-1077 \mathrm{o}_{\mathrm{K}}\right)+[9482.80 \pm 133.58] \\
& \text { for } 17000_{\mathrm{K}}<\mathrm{T}<2500{ }^{\circ} \mathrm{K}
\end{aligned}
$$

with units in cal per mole. As shown in Table 3 , the deviations from this linear fit were random and within expected variations. Equation 32 indicates a heat capacity of $7.42( \pm 0.14)$ calories per mole per degree for the temperature range between $1700{ }^{\circ} \mathrm{K}$ and $2500{ }^{\circ} \mathrm{K}$. The extrapolated 
Table 3. Results for liquid cerium between $1700^{\circ} \mathrm{K}$ and $2500{ }^{\circ} \mathrm{K}$ using solenoid levitation coll type $\mathrm{A}$ and $66 \%$ helium atmosphere

\begin{tabular}{|c|c|c|c|c|c|c|c|c|c|}
\hline $\begin{array}{l}\text { Run } \\
\text { No. }\end{array}$ & $\begin{array}{c}\text { Apparent } \\
\text { temperature } \\
\text { O }_{\mathrm{K}}\end{array}$ & $\begin{array}{c}\text { True } \\
\text { temperature } \\
\mathrm{o}_{\mathrm{K}}\end{array}$ & $\begin{array}{c}\text { Convection } \\
\text { losses } \\
\text { cal/mole }\end{array}$ & $\begin{array}{c}\% \\
\text { of: total } \\
\text { heat } \\
\text { content }\end{array}$ & $\begin{array}{l}\text { Radiation } \\
\text { losses } \\
\text { cal/mole }\end{array}$ & $\begin{array}{l}\% \\
\text { of total } \\
\text { heat } \\
\text { content }\end{array}$ & $\begin{array}{l}\text { Heat } \\
\text { content } \\
\text { cal/mole }\end{array}$ & $\begin{array}{l}\text { Smoothed } \\
\text { heat } \\
\text { content } \\
\text { cal/mole }\end{array}$ & $\begin{array}{c}\text { Dev. } \\
\%\end{array}$ \\
\hline 5 & 1553 & 1699 & 235 & 1.67 & -259. & 1.84 & 14046 & 14101 & -0.39 \\
\hline 6 & 1571 & 1721 & 238 & 1.64 & 271 & 1.86 & 14545 & 14264 & 1.93 \\
\hline 7 & 1593 & 1748 & 261 & 1.82 & 298 & 2.08 & 14339 & 14460 & -0.84 \\
\hline 4 & $1 \in 03$ & 1759 & 229 & 1.60 & 283 & 1.98 & 14298 & 14544 & -1.72 \\
\hline 9 & $1 \in 31$ & 1793 & 225 & 1.52 & 298 & 2.01 & 14798 & 14796 & 0.01 \\
\hline 11 & $1 \in 56$ & 1823 & 224 & 1.49 & 312 & 2.07 & 15054 & 15020 & 0.22 \\
\hline 8 & 16.68 & 1838 & 221 & 1.46 & 318 & 2.11 & 15090 & 15129 & -0.26 \\
\hline 14 & 16.85 & 1858 & 215 & 1.41 & 324 & 2.12 & 15262 & 15280 & -0.12 \\
\hline 1 & 1715 & 1896 & 206 & 1.33 & 336 & 2.16 & .15528 & 15558 & -0.19 \\
\hline 13 & 1745 & 1931 & 225 & 1.42 & 373 & 2.35 & 15862 & 15823 & 0.24 \\
\hline $40^{a}$ & 1762 & 1953 & 222 & 1.37 & 384 & 2.37 & 16196 & 15983 & 1.31 \\
\hline 10 & 1775 & 1968 & 206 & 1.28 & 377 & 2.35 & 16062 & 16097 & -0.22 \\
\hline 15 & 1810 & 2012 & 213 & 1.29 & 410 & 2.48 & 16551 & 16425 & 0.76 \\
\hline
\end{tabular}

${ }^{a}$ Values taken with conical levitation coil type A. 
Table 3. Continued

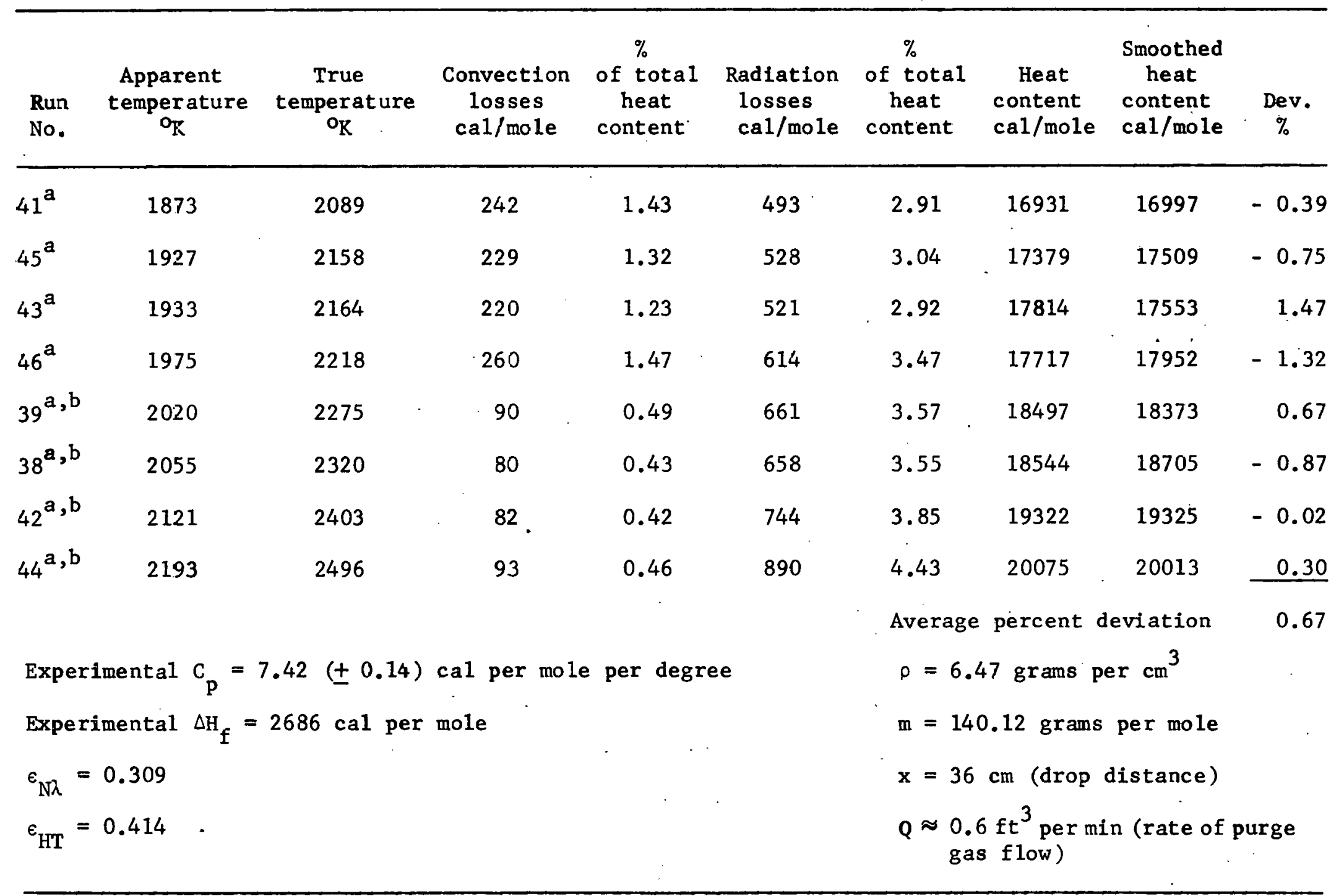

${ }^{\mathrm{B}}$ Values taken with $100 \%$ argon atmosphere. 
heat of fusion from these results is 2686 cal per mole. The magnitude of this value tends to further indicate the possibility that the heat content function is nonlinear with respect to temperature below $1700{ }^{\circ} \mathrm{K}$. Experimental results of heat content values below $1700{ }^{\circ} \mathrm{K}$ are given in Table 4. Included is coil types and calculated radiative and convective heat. losses.

Figure 11 illustrates the heat content of cerium from 298.15 to $2500{ }^{\circ} \mathrm{K}$ using the combined data of Mckeown (3) for the solid and liquid regions and the results of this work. The uncertainty region concerning the possibłe curving of the heat capacity function is from slightly above the melting point to $1700^{\circ} \mathrm{K}$. Figures 9 and 10 illustrate heat content values in the liquid phase determined in this work as compared to those of McKeown (3). Possible curvature below $1700^{\circ} \mathrm{K}$ is indicated in Figures 9 and 10 by the dashed line. Since the work of Chiotti et a1. (4) verifies the work of Mckeown (3) concerning the heat of fusion value for cerium, the possibility of this curvature existing becomes more probable.

Estimated thermodynamic function values between $1077 \mathrm{o}_{\mathrm{K}}$ and $1700 \mathrm{oK}^{\mathrm{K}}$ are given in 100 degree intervals in Table 5. The estimated heat capacity values in Table 5 have been derived from a polynomial curve which best fits the heat content data below $1700 \mathrm{o}$, including the heat content value found by McKeown (3) at 1077 o K. This value was chosen because of the heat of fusion verification obtained by Chiotti et al. (4). The resulting estimated heat content function in the temperature range $1077{ }^{\circ} \mathrm{K}$ to $1700{ }^{\circ} \mathrm{K}$ is given as 
Eable 4. Results for liquid cerium between $1400^{\circ} \mathrm{K}$ and $1700{ }^{\circ} \mathrm{K}$ using solenoid levitation coll type $\mathrm{A}$ and $100 \%$ helfum atmosphere

\begin{tabular}{|c|c|c|c|c|c|c|c|}
\hline $\begin{array}{l}\text { Run } \\
\text { No. }\end{array}$ & $\begin{array}{c}\text { Apparent } \\
\text { temperature } \\
O_{\mathrm{K}}\end{array}$ & $\begin{array}{c}\text { True } \\
\text { temperature } \\
\mathrm{O}_{\mathrm{K}}\end{array}$ & $\begin{array}{l}\text { Convection } \\
\text { losses } \\
\text { cal/mole }\end{array}$ & $\begin{array}{c}\% \\
\text { of total } \\
\text { heat } \\
\text { content }\end{array}$ & $\begin{array}{l}\text { Radiation } \\
\text { losses } \\
\text { cal/mole }\end{array}$ & $\begin{array}{c}\% \\
\text { of total } \\
\text { heat } \\
\text { content }\end{array}$ & $\begin{array}{c}\text { Heat } \\
\text { content } \\
\text { cal/mole }\end{array}$ \\
\hline 32 & 1298 & 1399 & 395 & 3.49 & 145 & 1.28 & 11314 \\
\hline $50^{a}$ & 1301 & 1403 & 435 & 3.75 & 154 & -1.33 & 11611 \\
\hline 31 & 1302 & 1403 & 363 & 3.17 & 139 & 1.21 & 11455 \\
\hline $48^{a}$ & 1334 & 1441 & 406 & 3.43 & 161 & 1.36 & 11850 \\
\hline $51^{a}$ & $13 \dot{4} 3$ & 1451 & 403 & 3.40 & 164 & 1.38 & 11853 \\
\hline $30^{b}$ & 1348 & 1457 & 259 & 2.10 & 172 & 1.39 & 12333 \\
\hline 34 & 1363 & 1474 & 396 & 3.19 & 170 & 1.37 & 12423 \\
\hline 33 & 1376 & 1489 & 426 & 3.36 & 183 & 1.44 & 12694 \\
\hline $49^{a}$ & 1386 & 1501 & 434 & 3.56 & 189 & 1.55 & 12189 \\
\hline $29^{b}$ & 1404 & 1522 & 292 & 2.23 & 210 & 1.61 & 13075 \\
\hline $47^{a}$ & 1419 & 1540 & 377 & 2.91 & 189 & 1.46 & 12963 \\
\hline $21^{b}$ & 1433 & 1556 & 274 & 2.09 & 217 & 1.66 & 13083 \\
\hline
\end{tabular}

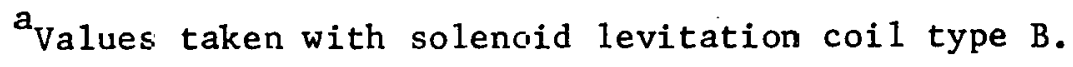

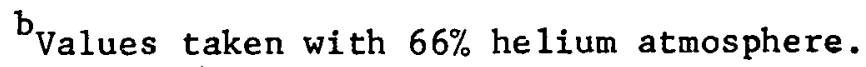


Table 4. Continued

\begin{tabular}{|c|c|c|c|c|c|c|c|}
\hline $\begin{array}{l}\text { Run } \\
\text { No. }\end{array}$ & $\begin{array}{c}\text { Apparent } \\
\text { temperature } \\
\text { oK }\end{array}$ & $\begin{array}{c}\text { True } \\
\text { temperature } \\
\mathrm{O}_{\mathrm{K}}\end{array}$ & $\begin{array}{c}\text { Convection } \\
\text { losses } \\
\text { cal/mole }\end{array}$ & $\begin{array}{c}\% \\
\text { of total } \\
\text { heat } \\
\text { content }\end{array}$ & $\begin{array}{l}\text { Radiation } \\
\text { losses } \\
\text { cal/mole }\end{array}$ & $\begin{array}{c}\% \\
\text { of total } \\
\text { heat } \\
\text { content }\end{array}$ & $\begin{array}{l}\text { Heat } \\
\text { content } \\
\text { cal/mole }\end{array}$ \\
\hline $28^{\mathrm{b}}$ & 1478 & 1610 & 278 & 2.06 & 240 & 1.78 & 13486 \\
\hline $2^{b}$ & 1510 & 1649 & 232 & 1.70 & 234 & 1.71 & 13659 \\
\hline$j^{b}$ & 1522 & 1662 & 246 & 1.81 & 248 & 1.82 & 13593 \\
\hline$\varepsilon_{\mathrm{N} \lambda}$ & 0.309 & \multicolumn{6}{|c|}{$\mathrm{m}=140.12 \mathrm{grams}$ per mole } \\
\hline $\begin{array}{l}\varepsilon_{\mathrm{HT}} \\
p=\end{array}$ & $\begin{array}{l}0.414 \\
7 \text { grams per }\end{array}$ & \multicolumn{6}{|c|}{$x=36 \mathrm{~cm}$ (drop distance) } \\
\hline
\end{tabular}




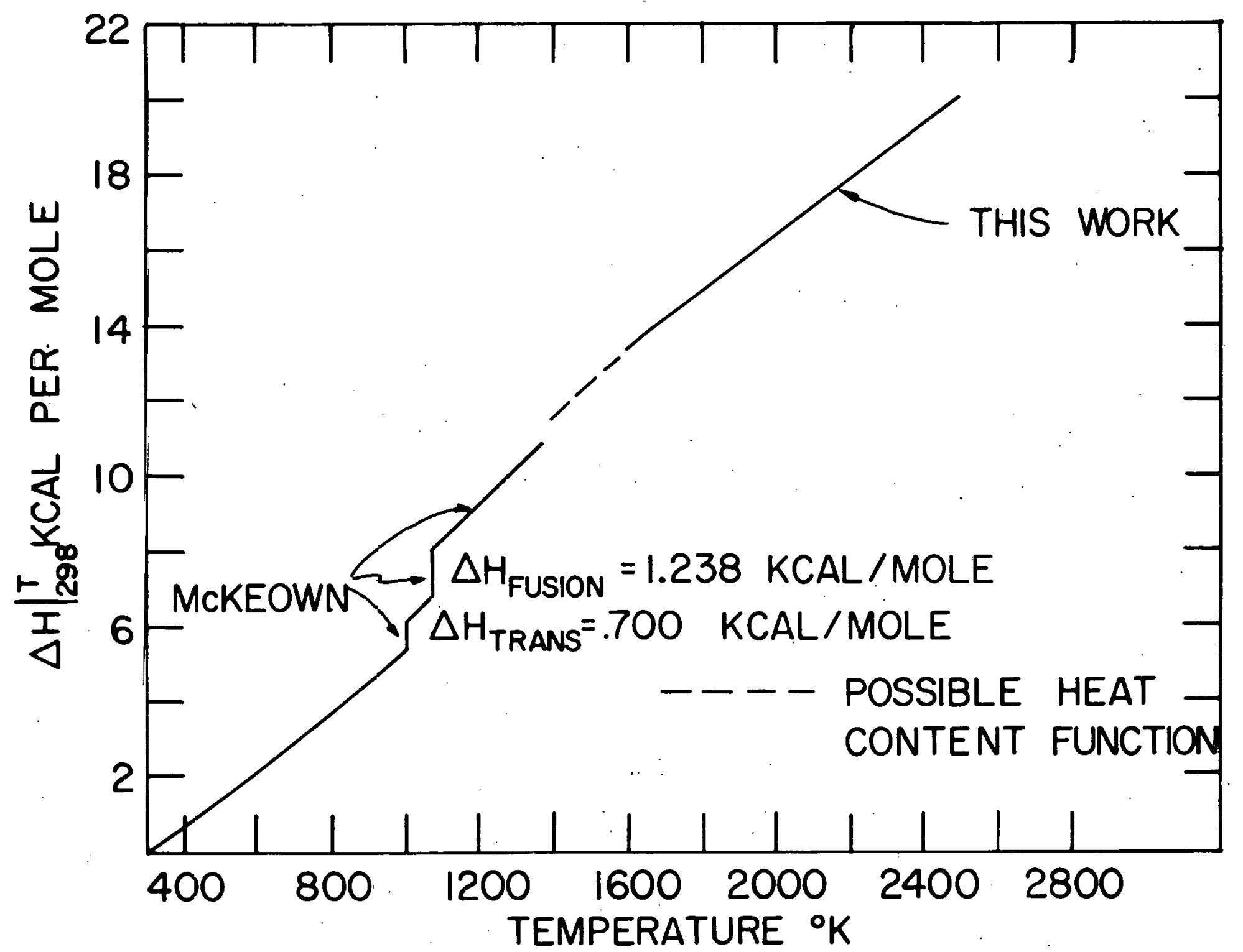

Bigure 11. Heat content of liquid cerium from $298.15^{\circ} \mathrm{K}$ to $2500^{\circ} \mathrm{K}$. 
Table 5. Estimated thermodynamic functions of liquid cerium between $1077^{\circ} \mathrm{K}$ and $1700{ }^{\circ}$. (cal per mole per degree)

\begin{tabular}{lcccc}
\hline $\mathrm{T}^{\mathrm{O}_{\mathrm{K}}}$ & $\mathrm{C}_{\mathrm{p}}$ & $\mathrm{S}_{\mathrm{T}}^{\mathrm{o}}-\mathrm{S}_{\mathrm{O}}^{\mathrm{O}}$ & $\frac{\mathrm{H}_{\mathrm{T}}^{\mathrm{O}}-\mathrm{H}_{298.15}}{\mathrm{~T}}$ & $-\frac{\left(\mathrm{F}_{\mathrm{T}}^{\mathrm{O}}-\mathrm{H}_{298.15}^{\circ}\right)}{\mathrm{T}}$ \\
\hline $1077^{\mathrm{a}}$ & 11.743 & 28.220 & 7.457 & 20.763 \\
1100 & 11.609 & 28.467 & 7.554 & 20.913 \\
1200 & 11.028 & 29.452 & 7.868 & 21.584 \\
1300 & 10.447 & 30.312 & 8.089 & 22.223 \\
1400 & 9.866 & 31.065 & 8.236 & 22.829 \\
1500 & 9.285 & 31.726 & 8.326 & 23.400 \\
1600 & 8.704 & 32.306 & 8.367 & 23.939 \\
1700 & 8.123 & 32.816 & 8.370 & 24.446. \\
\hline
\end{tabular}

$a_{\text {Values at }} 1077^{\circ} \mathrm{K}$ from Mckeown (3).

$$
\mathrm{H}_{\mathrm{T}}-\mathrm{H}_{298.15}=-0.0029 \mathrm{~T}^{2}+18 \mathrm{~T}-7975.3
$$

in cal per mole where $T$ is in degrees Kelvin. Figure 10 represents the estimated heat content function between $1077 \mathrm{o}_{\mathrm{K}}$ and $1700{ }^{\circ} \mathrm{K}$. The estimated heat capacity in this range is given as

$$
C_{p}=-0.00581 \mathrm{~T}+18
$$

in cal per mole per degree. The correlation coefficient for the curve fitting was 0.81 .

Thermodynamic function values between $1700{ }^{\circ} \mathrm{K}$ and $2500{ }^{\circ} \mathrm{K}$ are given in Table 6 . In this case the heat capac1ty is the slope of the experimental linear heat content data and is given as

$$
C_{p}=7.422 \text { cal per mole }
$$


Table 6. Thermodynamic function of liquid cerium between $1800^{\circ} \mathrm{K}$ and $2500{ }^{\circ} \mathrm{K}$ (cal per mole per degree)

$T$ oK $\quad C_{p} \quad\left(S_{T}^{\circ}-S_{0}^{0}\right)^{a} \quad\left(\frac{H_{T}^{O}-H_{298.15}^{O}}{T}\right)^{a} \quad\left(-\frac{\left(F_{T}^{O}-H_{298.15}^{O}\right)}{T}\right)^{a}$

\begin{tabular}{lllll}
\hline 1800 & 7.422 & 33.240 & 8.249 & 24.991 \\
1900 & 7.422 & 33.642 & 8.206 & 25.436 \\
2000 & 7.422 & 34.022 & 8.167 & 25.855 \\
2100 & 7.422 & 34.384 & 8.131 & 26.253 \\
2200 & 7.422 & 34.730 & 8.099 & 26.631 \\
2300 & 7.422 & 35.060 & 8.070 & 26.990 \\
2400 & 7.422 & 35.375 & 8.043 & 27.332 \\
2500 & 7.422 & 35.678 & 8.018 & 27.660 \\
\hline
\end{tabular}

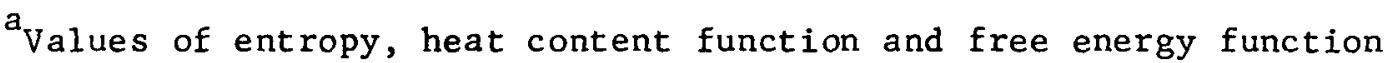
are based on the estimated values below $1700{ }^{\circ} \mathrm{K}$.

Heat capacity values between $298^{\circ} \mathrm{K}$ and $2500^{\circ} \mathrm{K}$ are given in Figure 12 according to Mckeown's (3) work between $298^{\circ} \mathrm{K}$ and $1375 \mathrm{oK}^{\circ}$ and this work from $1400^{\circ} \mathrm{K}$ to $2500 \%$ according to equations 34 and 35 .

The thermodynamic functions of Table 6 are based on the estimated values obtained in Table 5. The accuracy of these calculations are, therefore, limited to only approximations showing value trends and magnitudes. The thermodynamic functions were calculated according to the equations presented in the calculations section of this thesis.

The results of this work merited a review of experimental techniques and possible calculation errors. This analysis should help support the results obtained. 


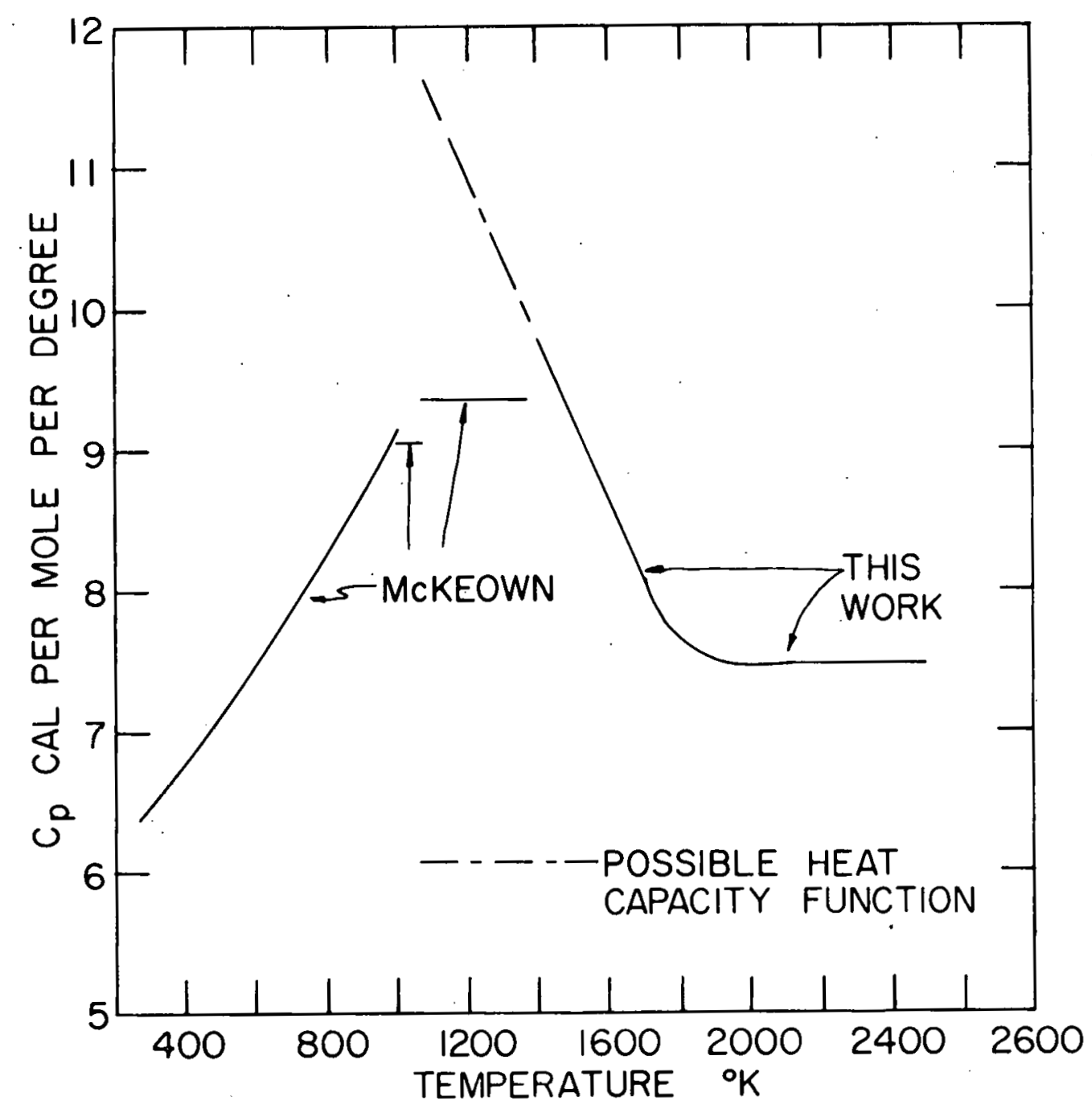

Figure 12. Heat capacity values of cerium from $2980_{\mathrm{K}}$ to $25000^{\circ}$. 
Experimental Evaluation

The results obtained from the copper calibration runs were in excellent agreement with the cited literature values including the recent work of Stephens (25). These results tend to eliminate the possibility of error in technique. This includes calibration, evaluation of the new sample dropping technique and the accuracy of sample temperature measurements .

The most probable source of error seems to be in establishing the true sample temperature. Therefore extended work was performed with the measured cerium temperature and its emittance values.

A test was made with a levitated sample of cerium to see if an apparent temperature change was indicated by the introduction of $5 \mathrm{c} . \mathrm{c}$. air into the levitation chamber under normal conditions with the purge gas at a normal flow rate and the power at a constant value. No apparent temperature increase was recorded by the pyrometer.

Vacuum fusion analysis before and after actual levitation runs indicated a $7.6 \times 10^{-5}$ grams increase in oxygen content of a 1 gram sample. The introduction of $5 \mathrm{c.c}$. of air into the system would be an approximate addition of $1 \times 10^{-3}$ grams of oxygen. This however does not discount the possibility of a surface film existing on a levitated samp le.

If such a film existed the emittance of a levitated sample could be altered. The effects of this film on the temperature are shown in Figure 13. Errors of $\pm 50 \%$ were introduced into the normal spectral emittance value of 0.309 . This extreme variation was used to illustrate 


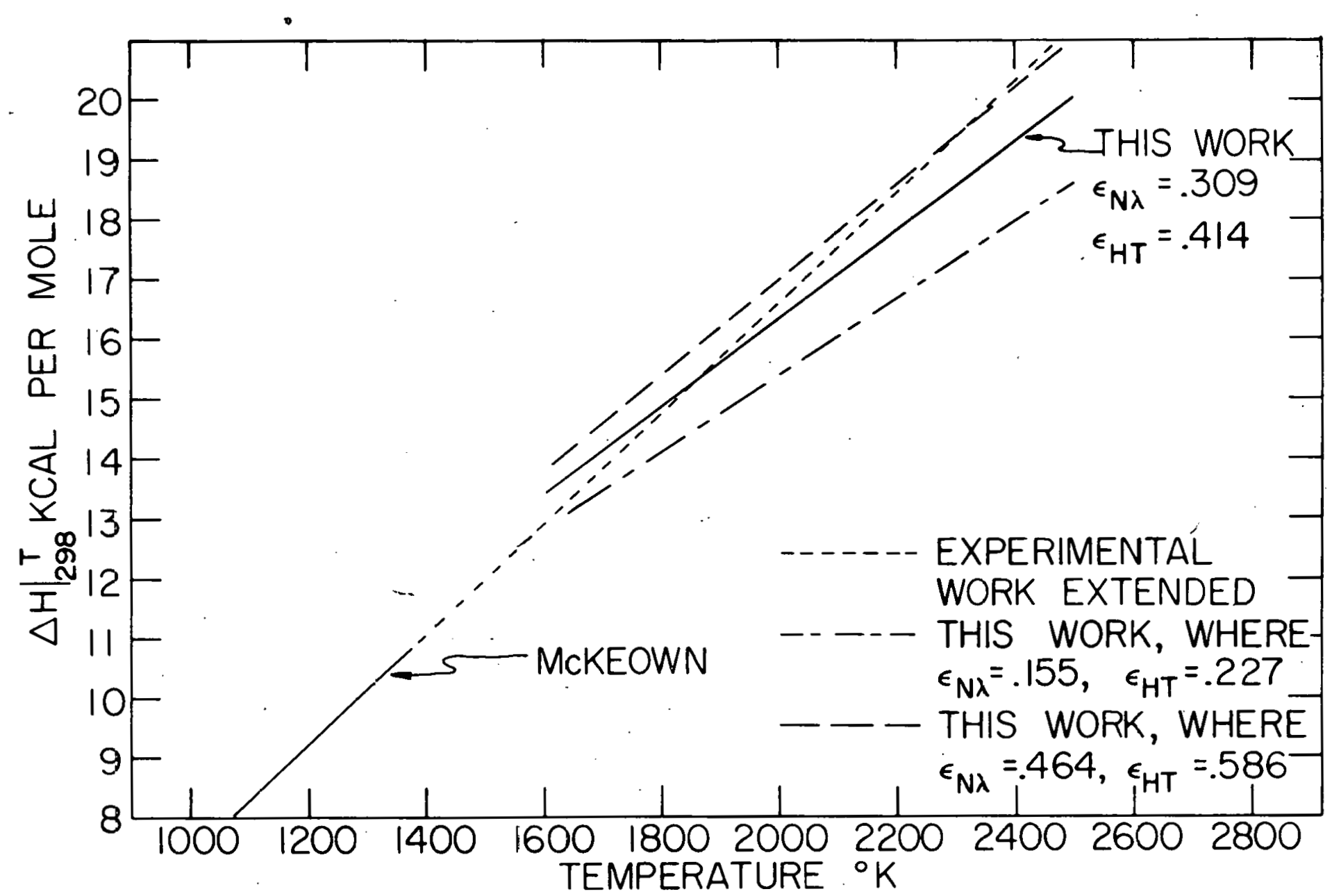

Figure 13. Analysis of $\pm 50 \%$ deviation in the normal spectral emittance of cerium. 
the effect on the measured heat content. As Figure 13 1llustrates neither deviation approaches the extended values of McKeown's

work. This indicates that the possibility of the normal spectral emittance being in error is very unlikely.

The possibility of hemispherical total emittance calculation errors are illustrated in Figure 14. Here the calculated hemispherical total emittance was varied by $\pm 20 \%$. Since this value is used only in the correction of heat content for radiative heat loss, only a slight variation is indicated.

Both of these considerations show that errors of less than $\pm 20 \%$ in either the normal spectral emittance and/or the calculation of the hemispherical total emittance would not alter the experimental results to values favorable to that of Mckeown (3).

The possibility of error in the liquid phase experimental work by Mckeown cannot be discounted. As previously discussed the purity of the water and mercury as well as the ability to maintain a constant volume calorimetric system govern the accuracy of this type of system. These possibilities plus inaccuracies in the heat loss correction could give unfavorable experimental results. Heat loss errors could be substantial in the liquid temperature region. Additional factors could be the dissolution of tantalum into the liquid cerium upon heating and the presence of thermal gradients through the sample and its tantalum crucible and platinum outer covering.

Although McKeown (3) has been proven successful for other materials, a question still exists as to its validity in cerium evaluation. Sample temperature measurement techniques, heat losses, 


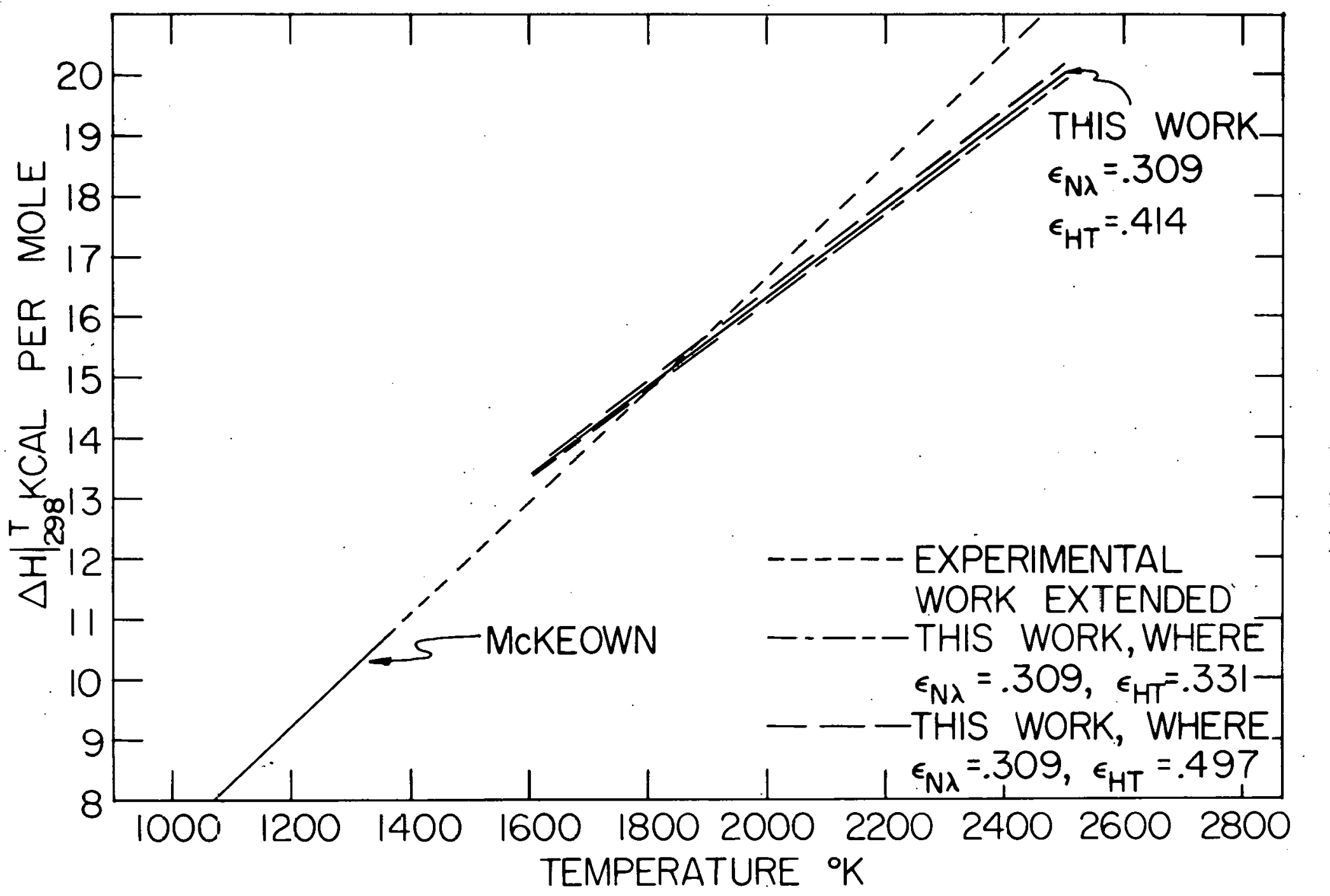

Figure 14. Analysis of $\pm 20 \%$ deviation in the hemispherical total emittance of cerium. 
and sample contamination seems to be an evident problem of previous work. This shows that the levitation calorimetry technique has advantages in regards to minimizing these possible errors. Reliable thermal emittance values and high sample purity will maintain accurate sample temperature readings. The corrections for radiative and convective heat losses including the calorimeter heat leakage is necessary for accurate results as shown in previous levitation calorimetry work. Tables 3 and 4 show the magnitude of radiative and convective heat losses for cerium runs. The accurate evaluation of these losses is critical in establishing accurate heat capacity data. Sample contamination is minimized since no container is involved. The container consists of the generated electromagnetic field and the purified inert gas system. The advantages of levitation calorimetry appear to warrant its future application in this type of thermodynamic research. 
SUMMARY AND CONCLUSIONS

Levitation calorimetry has been used to experimentally determine the heat content function of liquid cerium between $1400{ }^{\circ} \mathrm{K}$ and $2500{ }^{\circ} \mathrm{K}$. Previous experimental work (3) was limited to several experimental values $300^{\circ}$ above the melting point, $1077^{\circ} \mathrm{K}$.

The heat content function between $1700 \mathrm{oK}$ and $2500 \mathrm{o}_{\mathrm{K}}$ was found to be linear with respect to temperature. The heat content function in cal per mole is given as

$$
\begin{aligned}
& \mathrm{H}_{\mathrm{T}}-\mathrm{H}_{298.15}=[7.42 \pm 0.14]\left(\mathrm{T}-1077 \mathrm{O}_{\mathrm{K}}\right)+[9482.80 \pm 133.58] \\
& 1700 \mathrm{O}_{\mathrm{K}<\mathrm{T}<2500 \mathrm{OK}}
\end{aligned}
$$

The heat capacity for this temperature range is 7.42 cal per mole per degree.

The heat content function between $1400{ }^{\circ} \mathrm{K}$ and $17000^{\circ}$ was found to be nonlinear. The estimated heat content function for this temperature range in cal per mole is given as

$$
\begin{aligned}
& \mathrm{H}_{\mathrm{T}}-\mathrm{H}_{298.15}=-0.002905 \mathrm{~T}^{2}+18 \mathrm{~T}-7976.3 \\
& 1400 \mathrm{O}_{\mathrm{K}}<\mathrm{T}<1700 \mathrm{o}_{\mathrm{K}} .
\end{aligned}
$$

The estimated heat capacity in cal per mole per degree is given as

$$
\begin{gathered}
\mathrm{C}_{\mathrm{p}}=-0.00581 \mathrm{~T}+18 \\
1400 \mathrm{o}_{\mathrm{K}}<\mathrm{T}<1700 \mathrm{o}_{\mathrm{K}} .
\end{gathered}
$$

The experimental heat capacity above $1700{ }^{\circ} \mathrm{K}$ does approach the rule of thumb values of between 7 and $8 \mathrm{cal}$ per mole per degree. However the heat content function below 1700 oK does not agree with the experimental work performed by Mckeown. 
Alternate liquid state structures of cerium could be present up to a specific temperature in the liquid phase. These structures were previously mentioned as clustering. The history of clustering has been discussed in detail by Stretz (1). Clustering is mentioned as the near-solid association of large groups of atoms within the liquid phase. This possibility is of short range duration as opposed to long range.

The presence of short range clusters tend to yield higher heat capacity values than a homogeneous liquid phase. The results of this work between $14000^{\circ}$ and $1700{ }^{\circ} \mathrm{K}$ indicate a possible estimated heat capacity of $11.75 \mathrm{cal}$ per mole per degree at $1077 \mathrm{oK}$. This value would decrease to $7.42 \mathrm{cal}$ per mole per degree at $1800{ }^{\circ} \mathrm{K}$ and remain constant up to $25000^{\circ}$.

Although other experimental work with the lanthanide metals does not show this clustering effect, cerium could behave this way because it has two $4 \mathrm{f}$ electrons which could be quite unstable under these conditions. Secondy the electromagnetic stirring of the liquid sample could be of such magnitude with the other metals in the lanthanide series that the clustering is immediately dispersed. This immediate dispersion could be attributed to the additional $4 \mathrm{f}$ electrons in the other rare earth metals. The dispersion would tend to artificially flatten the heat content curve.

McKeown's (3) work between $1077^{\circ} \mathrm{K}$ and $1375{ }^{\circ} \mathrm{K}$ cannot discount this possibility due to possible errors as previously discussed. More experimental data in the temperature range $1077 \mathrm{o}_{\mathrm{K}}$ to $1400 \mathrm{o}_{\mathrm{K}}$ is needed to verify this possibility. The definite existence of clustering between $1077 \mathrm{o}_{\mathrm{K}}$ and $1700{ }^{\circ} \mathrm{K}$ could only be proven conclusively 
with further experimental work besides levitation calorimetry, such as high temperature $\mathrm{x}$-ray work.

Possible sources of error in levitation calorimetry work include errors in calorimeter calibration, errors in sample temperature determinations, errors in measurements of the calorimeter block temperature and errors introduced by approximations and estimates in the calculations. The largest source of error is in the measurement of the sample temperature. The maximum estimated error calculated by Stretz (1) for the levitation calorimetry work is $\pm 2.5 \%$.

The results of this work and other levitation calorimetry work have proven the need for extending liquid metals research by this technique. The void in high temperature liquid metal thermodynamic data will be filled as levitation calorimetry is applied to other systems of interest. 


\section{BIBLIOGRAPHY}

1. Stretz, L. A. 1973. High temperature heat content of selected rare earth metals by levitation calorimetry. Ph.D. Thesis. Iowa State University, Ames, Iowa.

2. Bonne11, D. W. 1972. Property measurements at high temperatures Levitation calorimetry studies of liquid metals. Ph.D. Thesls. Rice University, Houston, Texas.

3. Mckeown, J. J. 1958. The high temperature heat capacity and related thermodynamic functions of some rare earth metals. $\mathrm{Ph} . \mathrm{D}$. Thesis. Iowa State University, Ames, Iowa.

4. Chiotti, P., Gartner, G. J., Stevens, E. R. and Saito, Y. 1966. Heats of fusion and transformations for some metals and compounds. J. Chem. Eng. Data $11(4): 571-574$.

5. Cavallaro, U. 1943. Heat of fusion of $\mathrm{La}, \mathrm{Ce}, \mathrm{Pr}$ and $\mathrm{AI}$ (in Italian). Atti Accad. Italia Rend. 4:520.

6. Kelley, K. K. 1936. Heats of fuston of inorganic substances. U.S. Bur. of Mines Bul1. 393.

7. Vogel, R. 1917. Cerium-iron alloys (English surmary). J. Chem. Soc. 112 (II) : 259 .

8. Kelley, K. K. 1960. High-temperature heat content, heat capacity, and entropy data for the elements and inorganic compounds. U.S. Bur. of Mines Bu11. 584 .

9. Stu11, D. B. and Sinke, G. C. 1955. Thermodynamic properties of the elements. American Chemical Society. Advances in Chemistry Series 18,234 pp. 
10. Kojima, T. and Kikuchi, K. 1953. Metallurgical research on cerium metal (part 8) (in Japanese). J. Electochem. Soc. Japan, 21:177. 11. Sommer, F. 1973. Pseudo potential theory of the enthalpy of mixing of liquid alkali and earth alkali metal alloys. Acta Metallurgica $21: 1289$.

12. Dennison, D. H., Tschetter, M. J. and Gschneider, K. A. 1966. The solubility of tantalum and tungsten in rare earth metals. J. Less Comm. Metals 4:159.

13. Dennison, D. H., Gschneider, K. A. and Daane, A. H. 1966. Hightemperature heat contents and related thermodynamic functions of eight rare-earth metals: Sc, Gd, Tb, Dy, Ho, Er, Tm and Lu. J. Chem. Phys. $4: 4273-4282$.

14. Chaudhuri, A. K., Bonne11, D. W., Ford, L. A. and Margrave, J. L. 1970. Thermodynamic properties by levitation calorimetry. Enthalpy increments and heats of fusion for copper and platinum. High Temp. Sci. $2: 203-212$.

15. Treverton, J. A. and Margrave, J. L. 1971. Levitation calorimetry. The Thermodynamic properties of liquid cobalt and palladium. J. Phys. Chem. $75: 3737$.

16. Treverton, J. A. and Margrave, J. L. 1971. Thermodynamic properties by levitation calorimetry. The enthalpies of fusion and heat capacity for the liquid phases of iron, titanium and vanadium. J. Chem. Thermodynamics $1971(3): 473$.

17. Jenkins, A. E., Harris, B. and Baker, L. 1964. Electromagnetic levitation and its use in physico-chemical studies at high temperature. 
Symposium on Metallurgy at High Pressures and High Temperatures, Met. Soc. ATME Conf. $22: 23$ 。

18. Okress, E. C., Wroughton, D. M., Comenentz, G., Brace, P. and Kelley, J. C. R. 1952. Electromagnetic levitation of solid and molten metals. J. Applied Phys. $23: 545-552$.

19. Wroughton, D. M., Okress, E. C., Brace, P. H., Comenentz, G. and Kelley, J. C. R. 1952. A technique for eliminating crucibles in heating and melting metals. J. Electrochem. Soc. 99:205-211. 20. Stretz, L. A. 1970. Emissivity studies on selected rare earth metals. Unpublished M.S. Thesis. Iowa State University, Ames, Iowa. 21. Stretz, L. A. and Bautista, R. G. 1973. The emissivities of selected lanthanide metals at temperatures above their melting points. Fifth Symposium on Temperature, Its Measurement and Control in Science and Industry Proceedings, Part 1, 4:489-499.

22. Moscowitz, C. M., Stretz, L. A. and Bautista, R. G. 1972. The spectral emissivities of lanthanum, cerium and praseodymium. High Temp. Sci. $4(5): 372-378$.

23. Baria, D. No and Bautista, R. G. 1974. Compilation of experimental work on thcrmal emittances of macerials. Part 1 - Metals. USAEC Report IS -3346 .

24. Spedding, F. H., Beaudry, B. J., Croat, J. J. and Palmer, P. E. 1968. Materials technology - An interAmerican approach. Am. Soc. Mech. Eng., New York, New York. 151 pp.

25. Stephens, H. P. 1974. Determination of the enthalpy of liquid copper and uranium with a l1quid argon calorimeter. High Temp. Sc1. $6: 156-166$. 


\section{ACKNOWLEDGMENTS}

The author wishes to thank Dr. R. G. Bautista for his counsel during this investigation. Dr. P. Chiotti must be thanked for his interest and support concerning the results of this investigation. Thanks are also due to Mr. B. Beaudry for advice and cerlum sample preparation, Mr. N. Beymer for cerium impurity analysis, Mr. H. Jensen for technical assistance and Mr. G. Holland for advlce on high frequency generator operations. The author also wishes to express special appreciation to his wife, Evelyn, for her love and encouragement during the course of this work. 